\title{
TESTING OF NEUROPROTECTIVE \\ COMPOUNDS IN A TRANSGENIC MOUSE MODEL OF HUNTINGTON'S DISEASE
}

\author{
PhD Thesis
}

DÉNES ZÁDORI

Department of Neurology

Faculty of Medicine

Albert Szent-Györgyi Clinical Centre

University of Szeged

Szeged

2011 


\section{Publications directly related to the thesis}

I. Zádori D, Nyiri G, Szőnyi A, Szatmári I, Fülöp F, Toldi J, Freund TF, Vécsei L, Klivényi P (2011) Neuroprotective effects of a novel kynurenic acid analogue in a transgenic mouse model of Huntington's disease. J Neural Transm (in press; original paper; IF(2009): 2.259)

II. Zádori D, Geisz A, Vámos E, Vécsei L, Klivényi P (2009) Valproate ameliorates the survival and the motor performance in a transgenic mouse model of Huntington's disease. Pharmacol Biochem Behav 94: 148-53 (original paper; IF: 2.967)

Total impact factor of original papers directly related to the thesis: $\mathbf{5 . 2 2 6}$

\section{Publications not directly related to the thesis}

I. Zádori D, Klivényi P, Plangár I, Toldi J, Vécsei L (2011) Endogenous neuroprotection in chronic neurodegenerative disorders: with particular regard to the kynurenines. J Cell Mol Med (in press; review; IF(2009): 5.228)

II. Fülöp F, Szatmári I, Vámos E, Zádori D, Toldi J, Vécsei L (2009) Synthesis, transformations and pharmaceutical applications of kynurenic acid derivatives. Curr Med Chem 16: 4828-42 (review; IF: 4.708)

III. Zádori D, Klivényi P, Vámos E, Fülöp F, Toldi J, Vécsei L (2009) Kynurenines in chronic neurodegenerative disorders: future therapeutic strategies. J Neural Transm 116: 1403-9 (review; IF: 2.259)

IV. Vámos E, Vörös K, Zádori D, Vécsei L, Klivényi P (2009) Neuroprotective effects of probenecid in a transgenic animal model of Huntington's disease. J Neural Transm 116:107986 (original paper; IF: 2.259)

V. Hunya A, Földi I, Szegedi V, Soós K, Zarándi M, Szabó A, Zádori D, Penke B, Datki ZL (2008) Differences between normal and alpha-synuclein overexpressing SH-SY5Y 
neuroblastoma cells after Abeta(1-42) and NAC treatment. Brain Res Bull 75: 648-54 (original paper; IF: 2.281)

VI. Zádori D, Datki Z, Penke B (2007) The role of chronic brain hypoperfusion in the pathogenesis of Alzheimer's disease - facts and hypothesis. Ideggyogy Sz 60: 428-37 (review)

VII. Datki Z, Papp R, Zádori D, Soós K, Fülöp L, Juhász A, Laskay G, Hetényi C, Mihalik E, Zarándi M, Penke B (2004) In vitro model of neurotoxicity of Abeta 1-42 and neuroprotection by a pentapeptide: irreversible events during the first hour. Neurobiol Dis 17: 507-15 (original paper; IF: 4.389)

VIII. Datki Z, Juhász A, Gálfi M, Soós K, Papp R, Zádori D, Penke B (2003) Method for measuring neurotoxicity of aggregating polypeptides with the MTT assay on differentiated neuroblastoma cells. Brain Res Bull 62: 223-9 (original paper; IF: 2.609)

Cumulative impact factor: $\mathbf{2 8 . 9 5 9}$ 


\section{Table of contents}

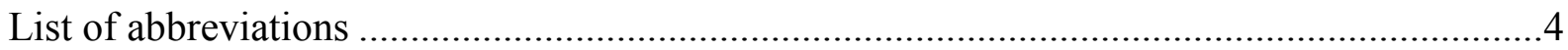

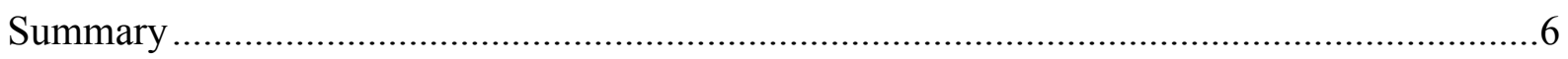

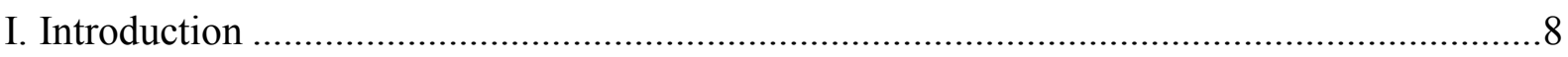

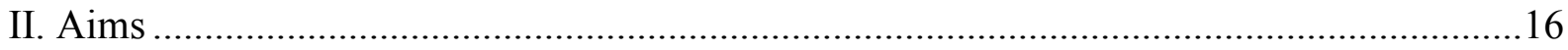

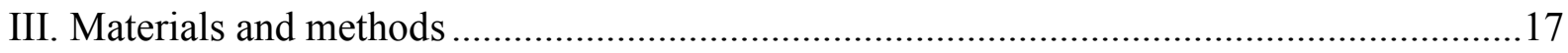

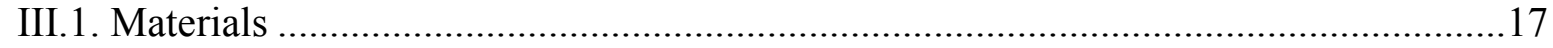

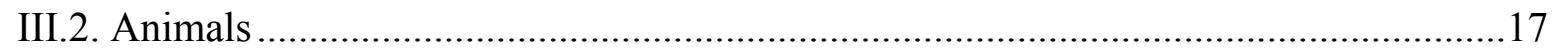

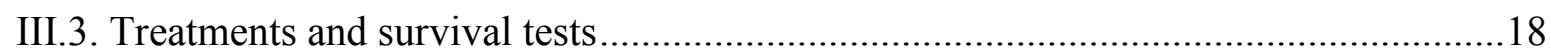

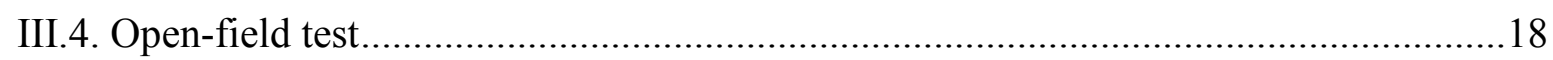

III.5. Testing for possible behavioural side-effects of valproate and the KYNA analogue in

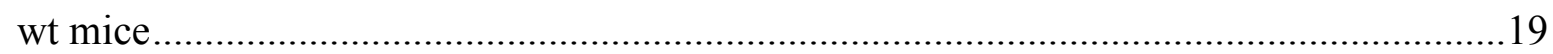

III.6. High-performance liquid chromatography (HPLC) measurements............................20

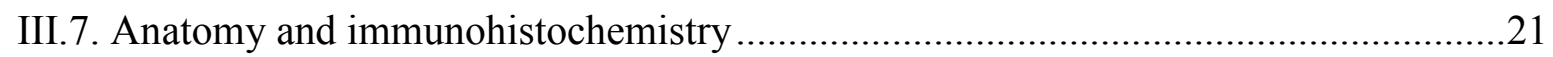

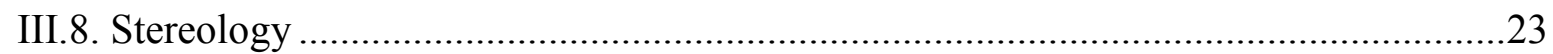

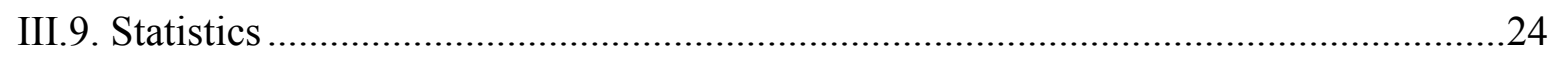

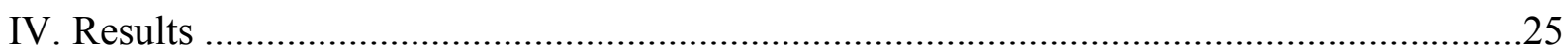

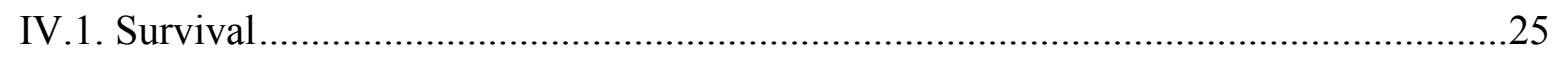

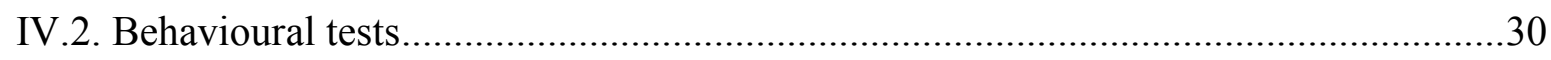

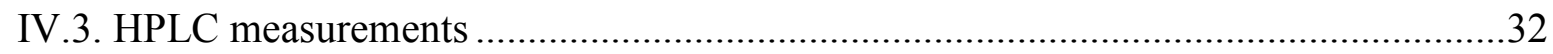

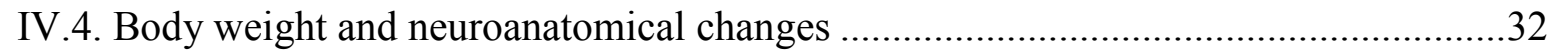

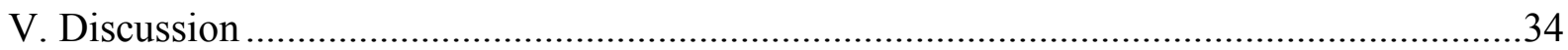

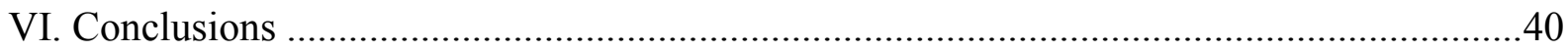

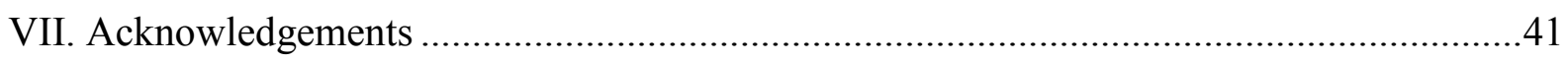

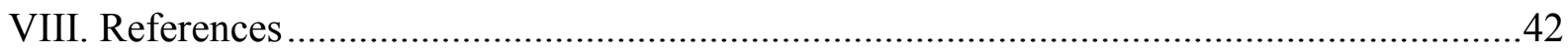




\section{List of abbreviations}

3-NP 3-nitropropionic acid

$\mathrm{A}_{\mathrm{i}} \quad$ area of the left striatum in the consecutive sections

ANOVA analysis of variance

asf area sampling fraction

CAG cytosine-adenine-guanine

CNS central nervous system

DA dopamine

DMSO dimethyl sulfoxide

DOPAC 3,4-dihydroxyphenylacetic acid

ER endoplasmic reticulum

GABA gamma-aminobutyric acid

HAT histone acetyltransferase

HD Huntington's disease

HDAC histone deacetylase

HPLC high-performance liquid chromatography

hsf height sampling fraction

HVA homovanillic acid

ip intraperitoneal

KAT kynurenine aminotransferase

KYNA kynurenic acid

L-KYN L-kynurenine

MPTP 1-methyl-4-phenyl-1,2,3,6-tetrahydropyridine

MSN medium-sized spiny neuron

$\mathrm{NAD}^{+} \quad$ nicotinamide adenine dinucleotide

NMDA $\quad N$-methyl-D-aspartate

NMDARs $\quad N$-methyl-D-aspartate receptors

PB phosphate buffer

PBS phosphate-buffered saline

PCR polymerase chain reaction

PGC1- $\alpha$ peroxisome proliferator-activated receptor gamma coactivator 1-alpha 


$\begin{array}{ll}\text { PPAR- } \gamma & \text { peroxisome proliferator-activated receptor gamma } \\ \text { QUIN } & \text { quinolinic acid } \\ \text { SEM } & \text { standard error of mean } \\ \text { SRS } & \text { stereotypy rating scale } \\ \text { ssf } & \text { section sampling fraction } \\ \text { TBS } & \text { Tris-buffered saline } \\ \text { tg } & \text { transgenic } \\ \mathrm{V}_{\mathrm{N}} & \text { neuronal volume } \\ \mathrm{V}_{\text {str }} & \text { striatal volume } \\ \text { wt } & \text { wild-type }\end{array}$




\section{Summary}

Huntington's disease (HD), the pathomechanism of which is not yet fully understood, is one of the chronic devastating neurodegenerative disorders. The pathophysiological processes clearly involve the formation of toxic aggregates, reduced gene transcription due to a decreased level of histone acetylation, a mitochondrial dysfunction and excitotoxicity, accompanied by the loss of gamma-aminobutyric acidergic (GABAergic) medium-sized spiny neurons in the striatum as a pathological hallmark of HD. Thus, the antiepileptic drug valproate, which has proved GABAergic, anti-excitotoxic and histone deacetylase inhibitor effects, the novel kynurenic acid (KYNA) analogue $N$-(2- $N, N$-dimethylaminoethyl)-4-oxo$1 H$-quinoline-2-carboxamide, which has probable complex anti-excitotoxic effects, the KYNA precursor blood-brain barrier penetrable L-kynurenine (L-KYN), which may also exert complex anti-excitotoxic effect after its transformation to KYNA, the natural dipeptide L-carnosine, which has antioxidant, antiglycator and metal chelator properties, the thiazolidinedione antidiabetic pioglitazone, which has a proved peroxisome proliferatoractivated receptor gamma activating effect, via which it can probably improve the mitochondrial function, and BZS1514, which can bind to the surface of $\beta$-sheet polyglutamine structures responsible for the toxicity of mutant huntingtin, might all be of value by exerting beneficial neuroprotective effects. We have now tested these drugs in the N171-82Q transgenic (tg) mouse model of HD, a model which replicates the characteristic phenomena of HD reasonably well as regards reduced longevity, disturbed spontaneous locomotor activity and pathological alterations. Following their chronic intraperitoneal (ip) administration in a daily dose of $100 \mathrm{mg} / \mathrm{kg}$, valproate and the novel KYNA analogue significantly prolonged the survival of the N171-82Q tg mice. Conversely, L-KYN, L-carnosine, pioglitazone and BZS1514, applied ip in doses of $100 \mathrm{mg} / \mathrm{kg}, 200 \mathrm{mg} / \mathrm{kg}, 5 \mathrm{mg} / \mathrm{kg}$ and $20 \mathrm{mg} / \mathrm{kg}$, respectively, did not lead to any significant amelioration in survival. Valproate and the KYNA analogue significantly ameliorated the diminished spontaneous locomotor activity of the N171-82Q tg mice, as measured by means of the open-field test. Indeed, valproate treatment significantly ameliorated the reduced exploratory activity, too. Neither valproate, examined by means of the open-field test and high-performance liquid chromatography (HPLC) measurements of the striatal level of dopamine and 2 of its metabolites, nor the novel KYNA analogue, examined by means of the open-field test, the elevated plus maze test and stereotypy rating scale, 
exerted any noteworthy side-effect in wild-type (wt) mice at the protective dose. As the neuroprotective effects of the novel KYNA analogue had never been verified before, a thorough anatomical analysis was also carried out. The results showed that the analogue prevented the loss of weight and completely prevented the atrophy of the striatal neurons. Although the findings indicate that the KYNA analogue rather exerted neuroprotective action, whereas the effects of valproate are mainly symptomatic, both substances led to clearly beneficial results. Those of valproate are probably explained by its complex GABAergic, antiexcitotoxic and histone deacetylase inhibitor effects, whereas those of the KYNA analogue are probably due to its complex anti-excitotoxic activity. Although the lack of efficacy in the cases of L-KYN, L-carnosine, pioglitazone and BZS1514 may be explained by subdosing, a more probable possibility is that these substances are unable to exert such marked effects in the applied HD model as valproate and the novel KYNA analogue. Although several previous clinical trials with valproate did not indicate any positive effect in HD, it is worth considering the design of new studies based on a well-planned treatment regime with a higher dose, using valproate in monotherapy or in combination therapy with a high number of participating patients. The novel KYNA analogue also appears worthy of further thorough investigations with a view to eventual clinical trials. 


\section{Introduction}

Huntington's disease (HD) is an autosomal dominantly inherited neurodegenerative disorder. Although the prevalence of HD is rather low $(\sim 5 / 100,000$; Folstein et al., 1987; Evers-Kiebooms et al., 2002), the disease displays a progressive nature and ends in certain death after a course of 15-20 years. Characteristically, it is manifested in cognitive, psychiatric and motor symptoms in middle-aged people (reviewed by Gardian and Vecsei, 2004; Walker, 2007). With regard to the motor symptoms, in addition to the loss of coordination of voluntary movements and the appearance of involuntary movements, a progressive gait impairment also develops, manifested in brady- and hypokinesia (Thompson et al., 1988; van Vugt et al., 1996). This alteration is particularly important, because it can lead to a loss of independence in motion, resulting in a constant need of care. The pathological alterations are mainly seen in the central nervous system (CNS), especially in the caudate nucleus, the putamen and the deeper layers of the cerebral cortex (Vonsattel et al., 1985). The loss of gamma-aminobutyric acidergic (GABAergic) medium-sized spiny neurons (MSNs) in the striatum (caudate nucleus + putamen) is the most pronounced feature (Reiner et al., 1988), resulting in a dysfunction of the basal ganglia circuits, and leading to the development of the characteristic symptoms (reviewed by Centonze et al., 2007).

HD is caused by the expansion of the cytosine-adenine-guanine (CAG) repeat in the gene coding for the $N$-terminal region of the huntingtin protein, which leads to the formation of a polyglutamine stretch. The gene was identified in 1993 (The Huntington's Disease Collaborative Research Group, 1993); it is located on the short arm of chromosome 4 (4p16.3) and was labelled interesting transcript 15. The function of the normal huntingtin protein is not fully known, but it definitely takes part in the intracellular $\mathrm{Ca}^{2+}$ signalling (Tang et al., 2003; Zhang et al., 2008), and plays an important role in the regulation of gene transcription (Zuccato et al., 2003). The physiological HD alleles comprise 6 to 35 CAGs, while alleles with 36 to $39 \mathrm{CAGs}$ are characterized by reduced penetrance. Above $39 \mathrm{CAGs}$, there is obligatory disease development. The greater the expansion, the earlier the disease is manifested (reviewed by Gardian and Vecsei, 2004). It has been shown that the mutant huntingtin protein interacts with numerous proteins which regulate important cellular

processes, thereby deteriorating their normal function (reviewed by Borrell-Pages et al., 2006). Cleavage of the mutant huntingtin protein by caspases and calpains results in the 
production of the $\mathrm{N}$-terminal fragments comprising the polyglutamine stretch (Wellington et al., 1998; Kim et al., 2001; Gafni and Ellerby, 2002). The expanded polyglutamine tracts undergo a conformational change, leading to the formation of a $\beta$-sheet structure from the helix-coil structure, so these fragments can form oligomers and polymers, such as nuclear aggregates (those of pronounced size are known as intranuclear inclusions), and also perikaryal and neuropil aggregates (DiFiglia et al., 1997; Gutekunst et al., 1999). However, it is doubtful whether monomers, oligomers or large inclusions are the toxic species (reviewed by Hoffner et al., 2007; Truant et al., 2008). The soluble monomers and oligomers surely have toxic properties (Nagai et al., 2007; Takahashi et al., 2008), while the role of large inclusions in toxicity is still questionable, because some researchers argue for a toxic role due to the sequestration of important proteins in aggregates, while others argue for a protective role due to localization of the toxic soluble mutant protein to insoluble and inactive reservoirs.

The mutant huntingtin has been shown to interact with proteins which regulate transcription (reviewed by Cha, 2000; Kazantsev and Hersch, 2007). One group of these proteins is the histone acetyltransferases (HATs; Igarashi et al., 2003). The posttranslational acetylation of histones by HATs at lysine residues results in the neutralization of those positively charged proteins, leading to a more open conformation of the deoxyribonucleic acid, allowing the binding of transcription factors. The histone deacetylases (HDACs) remove the acetyl groups, which results in a reduced ability to bind the transcription factors, and thus the transcription processes become considerably reduced. There is increasing evidence that an altered balance between HAT and HDAC activity may accompany the development of neurodegenerative disorders, including HD (reviewed by Langley et al., 2005; Sadri-Vakili and Cha, 2006). The inhibition of HDACs may restore of the altered balance described above, as the application of such substances has been found to arrest the polyglutamine-dependent neurodegeneration in models of polyglutamine disease (Steffan et al., 2001; Ferrante et al., 2003; Hockly et al., 2003; Gardian et al., 2005; Thomas et al., 2008).

An early finding suggestive of the involvement of a mitochondrial dysfunction in the development of HD was a decreased activity of succinate dehydrogenase (complex II of the electron transport chain) in post-mortem HD brains (Stahl and Swanson, 1974). Mutant huntingtin has been shown to be able to bind directly to mitochondria, thereby altering their normal function (Orr et al., 2008). The impaired mitochondrial $\mathrm{Ca}^{2+}$ handling (Panov et al., 
2002) and the repression of transcription factors, e.g. that responsible for peroxisome proliferator-activated receptor gamma (PPAR- $\gamma$ ) coactivator 1-alpha (PGC1- $\alpha$; involved in the regulation of gene expression related to mitochondrial biogenesis and respiration; Cui et al., 2006), are certainly associated with the mitochondrial dysfunction in HD. It seems that PPAR- $\gamma$ agonists are capable of the activation of PGC1- $\alpha$ with the possibility of disease amelioration (reviewed by Kiaei, 2008).

Glutamate-induced excitotoxicity seems to play an important role in the development of HD (Coyle and Schwarcz, 1976; McGeer and McGeer, 1976; reviewed by DiFiglia, 1990). To explain the selective impairment of the MSNs, it should be borne in mind that they receive a massive glutamatergic input from the cortex (Fonnum et al., 1981) and the thalamus (reviewed by Smith et al., 2004). As the $N$-methyl-D-aspartate (NMDA) receptors (NMDARs) are to be found in especially high amount on the spines of the MSNs (Landwehrmeyer et al., 1995), these neurons are rather sensitive to glutamate (Zeron et al., 2002; Shehadeh et al., 2006), which explains the extremely extensive loss of striatal neurons expressing NMDARs (Young et al., 1988). Furthermore, the expression pattern of the receptor subunits differs from those of the other striatal neurons (Landwehrmeyer et al., 1995; Kuppenbender et al., 2000), as the extrasynaptic NMDARs of MSNs preferentially contain the NR2B subunits (Okamoto et al., 2009; Milnerwood et al., 2010). The available data suggest that synaptic NMDAR activation promotes neuronal survival, while the activation of NMDARs at the extrasynaptic site is neurotoxic (Hardingham et al., 2002). Furthermore, there is accumulating evidence that glutamate-induced excitotoxicity is mainly mediated by the NR2B subunit-containing NMDAR channels (Liu et al., 2007). The expression of mutant huntingtin can sensitize the NR2B subunit-containing NMDARs (Chen et al., 1999; Song et $a l ., 2003$ ), thereby aggravating the excitotoxic process (Heng et al., 2009). Additionally, the polyglutamine expansion has been found to interfere with the ability of huntingtin to interact with the postsynaptic density protein of $95 \mathrm{kDa}$ (Sun et al., 2001), a structural link between neuronal nitric oxide synthase and NMDARs (Sattler et al., 1999), which also results in the sensitization of NMDARs. Further, mutant huntingtin can increase $\mathrm{Ca}^{2+}$ release from the endoplasmic reticulum (ER), by binding to the inositol triphosphate receptor 1 (Tang et al., 2003). Glutamate excitotoxicity can be influenced to a great extent by the metabolites of the kynurenine pathway, the main pathway of the tryptophan metabolism (Fig. 1; reviewed by 
Schwarcz et al., 2010). One of the neurochemical features of HD is the imbalance of the tryptophan metabolism in the striatum in different stages of the disease. A relative decrease in kynurenic acid (KYNA) level and a reduced activity of kynurenine aminotransferase (EC 2.6.1.7, KAT), the enzyme responsible for KYNA biosynthesis, have been demonstrated in the striatum of HD patients (Beal et al., 1990; Jauch et al., 1995; Guidetti et al., 2004). These alterations have been suggested to be related to the development of the disease. A severe reduction in KAT-I immunoreactivity has also been revealed in the rat striatum after chronic 3-nitropropionic acid (3-NP) treatment (Csillik et al., 2002). It has also been postulated that quinolinic acid (QUIN) may be the endogenous neurotoxin in HD (reviewed by Schwarcz et $a l ., 2010)$. It may exert its deleterious effects via direct activation of the NR2A and NR2B subunit containing NMDA receptors (Stone and Perkins, 1981; de Carvalho et al., 1996). Furthermore, QUIN can facilitate the release of glutamate or can inhibit its uptake (Connick and Stone, 1988; Tavares et al., 2002). Accordingly, intrastriatal administration of QUIN can be used as a model of HD (Schwarcz et al., 1983; Beal et al., 1986; Vecsei and Beal, 1991a), mainly as concerns the early symptoms of the disease (Bordelon and Chesselet, 1999). Mice with the genomic deletion of another KYNA-producing enzyme, KAT-II, displayed an increased neuronal vulnerability to the intrastriatal administration of QUIN, which suggests the importance of KYNA in controlling the neurotoxicity of QUIN (Sapko et al., 2006). This is supported by the fact that an increase in KYNA concentration proves protective in the QUIN model (Harris et al., 1998).

At present, only symptomatic therapy is available in HD, with neuroleptics, dopaminedepleting agents, antidepressants, antiglutamatergic drugs, $\gamma$-aminobutyric acid agonists, antiepileptics, acetylcholinesterase inhibitors and the botulinum toxin (reviewed by Adam and Jankovic, 2008). A number of agents have proved protective in transgenic models, and have recently been tested in early-phase clinical trials. Depending on the molecular mechanism of their effect, the aims mostly involve the inhibition of transcription and histone deacetylation, the achievement of marked antioxidant and anti-excitotoxic effects, improvement of the mitochondrial function and the prevention of an energy impairment (reviewed by Hersch and Ferrante, 2004). Furthermore, there are also strategies to prevent the effects of toxic species of polyglutamine-expanded proteins (reviewed by Truant et al., 2008). However, most of the clinical trials failed to prove any efficacy in the amelioration of disease progression. 


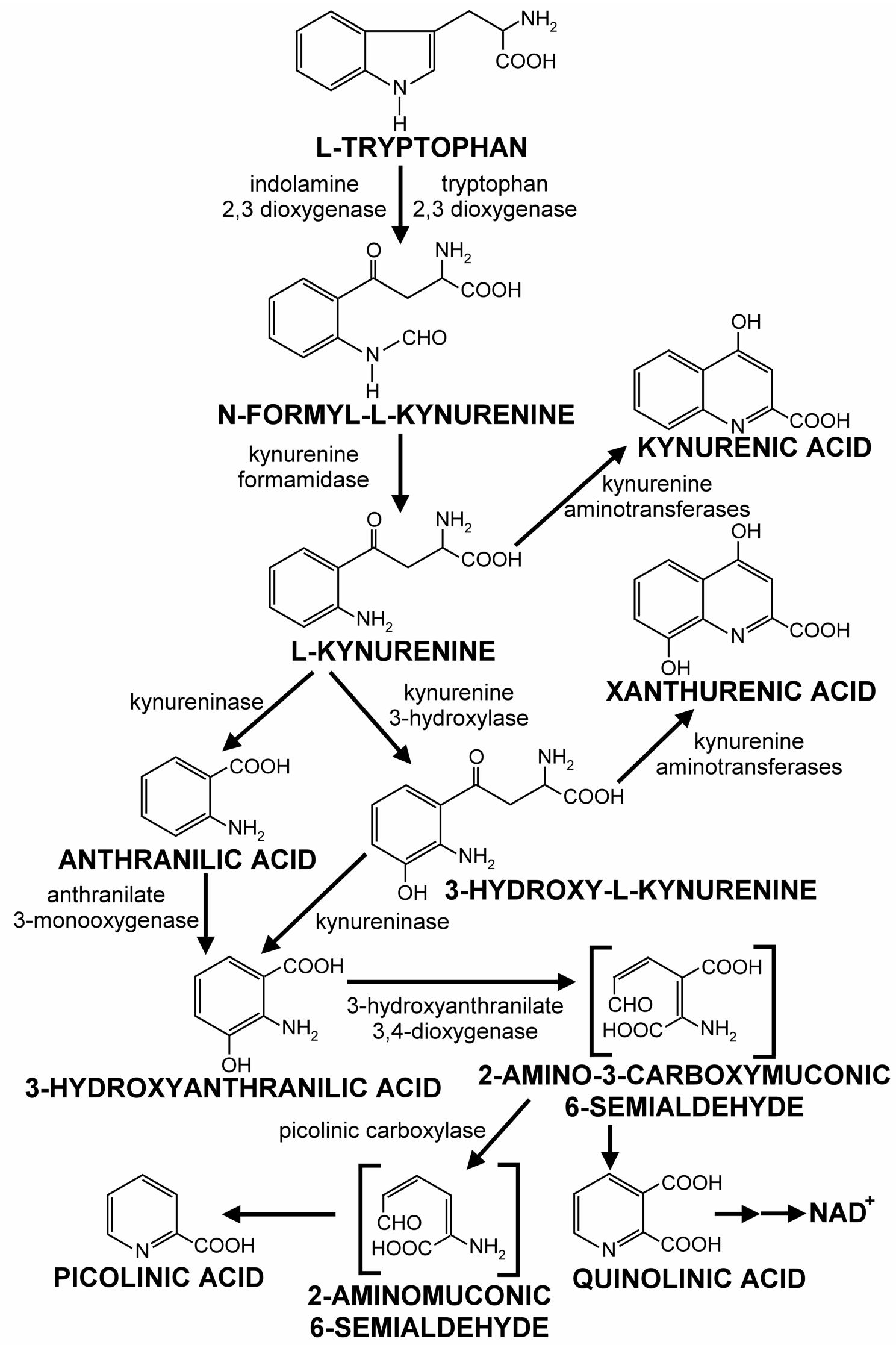

Figure 1. The kynurenine pathway of the tryptophan metabolism. 
As concerns rodent models of $\mathrm{HD}$, we can distinguish between toxin and genetic models. The toxin models include those primarily inducing a mitochondrial dysfunction by the reversible (malonate; Beal et al., 1993a) or irreversible (3-NP; Gould and Gustine, 1982; Beal et al., 1993b) inhibition of complex II of the electron transport chain, and those inducing primarily glutamate excitotoxicity (kainate; Coyle and Schwarcz, 1976; McGeer and McGeer, 1976; ibotenic acid; Schwarcz et al., 1979; QUIN; Beal et al., 1986). Although these models can serve as simple and rapid testing tools, they have a great limitation as they do not involve the underlying genetic mutation. By the use of genetic models, including transgenic (tg; Mangiarini et al., 1996; Schilling et al., 1999; Hodgson et al., 1999; von Horsten et al., 2003), knock-in (Wheeler et al., 1999; Lin et al., 2001; Menalled et al., 2003) and lentiviralmediated mutant huntingtin (de Almeida et al., 2002) models, this problem can be got around. However, some of these models show only slow disease progression, which hampers the rapid testing of potentially neuroprotective compounds. Nevertheless, the use of R6/2 (Mangiarini et al., 1996) or N171-82Q (Schilling et al., 1999) tg mice can provide a solution to this problem. The N171-82Q tg line was created through the use of $N$-terminally truncated human huntingtin cDNA, which encodes 82 glutamines and encompasses the first 171 amino acids under the control of a mouse prion protein promoter. As an animal model of HD, we used N171-82Q tg mice, because their slighter phenotype as compared with R6/2 tg mice provides a greater chance for the tested compounds to be able to exert their beneficial effects, if they have any. Characteristically, the symptoms begin to develop at approximately 2 months of age. The weight of the mice does not subsequently increase further, while tremor, reduced locomotor activity and difficulties in coordination evolve, and the gait becomes abnormal (Schilling et al., 1999). It may be mentioned here that the reduced locomotor activity and exploratory behaviour can be well tested in the open-field paradigm (Klivenyi et al., 2006). At an advanced stage, the body weight decreases, and the animals die at an average age of 110-130 days. The pathological aggregation processes closely resemble those in human cases. This tg model of HD therefore seems to be appropriate for the testing of drug effects on survival, gait impairment and histopathological alterations.

2-Propylpentanoic acid (valproate) is a widely used antiepileptic drug, although it is also applied in other indications, such as bipolar disorders, migraine and chronic neuropathic pain (reviewed by Johannessen and Johannessen, 2003). Its pharmacological action is exerted 
via a very complex mechanism (reviewed by Loscher, 1999; Kostrouchova et al., 2007). It can increase brain GABA levels (Taberner et al., 1980) through the reduction of GABAtransaminase, increasing the glutamate decarboxylase activity (Loscher, 1981a; 1981b), and it can potentiate the release of GABA (Gram et al., 1988). Furthermore, valproate can suppress NMDA-evoked transient depolarizations (Zeise et al., 1991), and it can therefore exert a dosedependent neuroprotective effect against excitotoxicity (Hashimoto et al., 2002). In addition, valproate can exert effects on the brain dopamine (DA) concentrations, too (Vriend and Alexiuk, 1996). Besides the effects detailed above, valproate can influence multiple regulatory pathways. In this manner, probably its most important effect is the inhibition of HDACs (Kramer et al., 2003); it selectively inhibits the catalytic activity of class I HDACs and induces the proteasomal degradation of class II HDACs.

Tg mouse models of HD replicate the disturbance in the tryptophan metabolism rather well (Guidetti et al., 2006). A relative deficiency of the neuroprotective KYNA is a characteristic feature of most of these models, which raises the possibility that increasing the effect of KYNA would be beneficial from a therapeutic aspect. The protective effects of KYNA appear to be due to its broad-spectrum endogenous antagonism on ionotropic excitatory amino acid receptors (Perkins and Stone, 1982; Birch et al., 1988). KYNA can inhibit NMDA receptors at the glycine-binding sites (Kessler et al., 1989) and it can noncompetitively inhibit $\alpha 7$-nicotinic acetylcholine receptors, too (Hilmas et al., 2001). Blockade of these nicotinic receptors can also mediate the inhibition of glutamate release in the striatum (Marchi et al., 2002). However, the systemic administration of KYNA does not seem a good therapeutic approach for several reasons. In higher doses, its solubility is a limiting factor, it penetrates the blood-brain barrier poorly (Fukui et al., 1991), and it undergoes a rapid clearance from the brain and the body, this clearance being mediated by organic anion transporters (Bahn et al., 2005). To overcome these disadvantages, an amide analogue bearing a water-soluble side-chain, 2-N,N-dimethylaminoethylamine, in the amide moiety, has been synthesized (Fig. 2). The intracerebroventricular injection of KYNA per se reduces exploratory activity, and induces ataxia and stereotypy in rats (mainly at higher doses; Vecsei and Beal, 1991b), and KYNA has also been shown to be an anxiolytic (Schmitt et al., 1990). The possible changes in these aspects of behaviour following the treatment with the KYNA analogue may influence the motor performance of mice. The possible therapeutic use of the 
KYNA precursor L-kynurenine (L-KYN) emerges, because it readily crosses the blood-brain barrier and can be transformed to KYNA by the action of KATs.

L-Carnosine ( $\beta$-alanyl-L-histidine) is a dipeptide with demonstrated antioxidant, antiglycator and metal chelator properties (reviewed by Boldyrev et al., 2010). Due to this complex mechanism of action, it is perhaps capable of ameliorating the oxidative damage characteristic of HD.

Pioglitazone is a widely used thiazolidinedione antidiabetic, which has a proved PPAR- $\gamma$ activating effect (reviewed by Higgins and Depaoli, 2010). Although another substance from this group, rosiglitazone, showed no efficacy in the R6/2 mouse model of HD (Hunt and Morton, 2005), this substance can hardly cross the blood-brain barrier. Pioglitazone can penetrate the blood-brain barrier considerably better, so it would be more suitable for neuroprotective purposes.

The detrimental effects of the $\beta$-sheet structure and the consequential aggregation may be mitigated by ligands binding to the surface of this structure. Researchers at the Department of Medicinal Chemistry, University of Szeged and those at the Protein Chemistry Research Group, Hungarian Academy of Sciences (Szeged, Hungary), set up an antiparallel $\beta$-sheet structure monomer model connecting 4 glutamine7 units by $3 \beta$-turn structures with the help of the Beta-Sheet Builder program. This structure is consistent with that published earlier based on X-ray diffraction measurements (Sharma et al., 2005). The binding of the selected compounds was examined with the aid of the Autodock 4 program (Morris et al., 1998; Huey et al., 2007). The blind docking (Hetenyi and van der Spoel, 2002) was performed on the entire surface of the glutamine40 molecule. Accordingly, through the use of the simulation model, several compounds were selected which would be applicable in the amelioration of polyglutamine-induced toxic effects. One of these compounds is BZS1514. 


\section{Aims}

The aims of our studies were as follows:

(i) To study the effects of valproate, the KYNA analogue $N$-(2-N,N-dimethylaminoethyl)-4oxo-1H-quinoline-2-carboxamide, L-KYN, L-carnosine, pioglitazone and BZS1514 on the survival of N171-82Q tg mice.

(ii) To examine the effects of those substances which significantly prolonged the survival (valproate and the KYNA analogue) on the characteristic behavioural changes (decreased spontaneous locomotor and reduced exploratory activity) in N171-82Q tg animals.

(iii) To exclude the additional effects of the treatment (valproate and the KYNA analogue) itself, i.e. other than those due to symptom amelioration, on spontaneous locomotor and exploratory activity, using wild-type (wt) mice. We investigated the possible anxiolytic and stereotypy-inducing effects of the KYNA analogue, too.

(iv) To measure the striatal levels of DA and 2 of its metabolites after chronic valproate administration.

(v) To investigate thoroughly the effects of the KYNA analogue on anatomical and histopathological alterations characteristic of the N171-82Q tg mouse model of HD by means of body and brain weight analyses and unbiased design-based stereological procedures. 


\section{Materials and methods}

\section{III.1. Materials}

Sodium valproate was obtained in the form of powder for injections (Depakine; Sanofi Winthrop Industrie, Gentilly, France). The KYNA analogue $N-(2-N, N-$ dimethylaminoethyl)-4-oxo- $1 H$-quinoline-2carboxamide hydrochloride (Fig. 2) was synthesized from KYNA in the Department of<smiles>CN(Cl)CCNC(=O)c1cc(=O)c2ccccc2[nH]1</smiles>

Figure 2. The chemical structure of $N-(2-N, N-$ dimethylaminoethyl)-4-oxo-1H-quinoline-2carboxamide hydrochloride.

Pharmaceutical Chemistry, University of Szeged (Szeged, Hungary). The synthetic procedure involved an amidation reaction between KYNA and $N, N$-dimethylethylenediamine in dimethylformamide in the presence of 1-hydroxybenzotriazole by using $N, N^{\prime}$ diisopropylcarbodiimide as coupling reagent, followed by chromatographic purification. LKYN-sulfate (K3750) and L-carnosine (C9625) were purchased from Sigma-Aldrich Hungary Ltd. (Budapest, Hungary). Pioglitazone hydrochloride was a kind gift of Takeda Pharmaceutical Co., Ltd. (Osaka, Japan). BZS1514 was synthesized in the Department of Medicinal Chemistry, University of Szeged (Szeged, Hungary).

\section{III.2. Animals}

N171-82Q (also known as B6C3-Tg(HD82Gln)81Dbo/J) tg mice (Jackson Laboratories, Bar Harbor, ME, USA) were maintained on the B6C3F1 wt background in our laboratory and the genotype was identified by polymerase chain reaction (PCR) from tail biopsies (Fig. 3). The mice were housed in cages (at most 5 per cage), with free access to food and water, under standard conditions. Male and female mice were distributed equally between the experimental groups. All animal experiments were carried out in accordance with the European Communities Council Directive (86/609/EEC) and were approved in advance by the local animal care committee.

Figure 3. PCR gel identifying the presence of the transgene. The first 2 columns represent negative wt animals, and the third column a positive tg animal. (The numbers in the picture denote the base pair lengths of the ladder strands.) 


\section{III.3. Treatments and survival tests}

We tested the 6 agents (valproate, KYNA analogue, L-KYN, L-carnosine, pioglitazone and BZS1514) in 5 separate experiments (the survival testing of the KYNA analogue and L-KYN were carried out in the same study). The treated N171-82Q tg mice received intraperitoneal (ip) injections of valproate $(n=8 ; 100 \mathrm{mg} / \mathrm{kg} / \mathrm{day}$, in a volume of 5 $\mathrm{ml} / \mathrm{kg}$, dissolved in saline), the KYNA analogue $(n=10 ; 100 \mathrm{mg} / \mathrm{kg} / \mathrm{day}$, in a volume of 5 $\mathrm{ml} / \mathrm{kg}$, dissolved in distilled water, and the $\mathrm{pH}$ of the solution was adjusted to 6.5 with $1 \mathrm{~N}$ $\mathrm{NaOH}), \mathrm{L}-\mathrm{KYN}(n=10 ; 100 \mathrm{mg} / \mathrm{kg} / \mathrm{day}$, in a volume of $5 \mathrm{ml} / \mathrm{kg}$, dissolved in $0.1 \mathrm{M}$ phosphate-buffered saline (PBS), and the $\mathrm{pH}$ of the solution was adjusted to 7.0 with $1 \mathrm{~N}$ $\mathrm{NaOH})$, L-carnosine ( $n=14 ; 200 \mathrm{mg} / \mathrm{kg} /$ day, in a volume of $5 \mathrm{ml} / \mathrm{kg}$, dissolved in PBS), pioglitazone $(n=10 ; 5 \mathrm{mg} / \mathrm{kg} / \mathrm{day}$, in a volume of $5 \mathrm{ml} / \mathrm{kg}$, suspended in $0.1 \%(\mathrm{wt} / \mathrm{vol})$ carboxymethylcellulose solution) or BZS1514 ( $n=8 ; 20 \mathrm{mg} / \mathrm{kg} /$ day, in a volume of $5 \mathrm{ml} / \mathrm{kg}$, dissolved in saline). The compounds were administered at the same time each day, 5 days per week, from 7 weeks of age. The examination of the effects of each compound on longevity in N171-82Q tg mice was controlled by using vehicle-treated N171-82Q tg mice $(n=8, n=10$, $n=10, n=14, n=10, n=8$, according to the above list of agents). Furthermore, in order to exclude other possible causes of death than those due to the presence of the transgene, we used wt littermates, too $(n=7, n=10, n=10, n=12, n=12, n=8$, according to the above list of agents). The possible toxicity of the administered agents in the applied doses was also excluded in background studies using wt littermates $(n=8, n=8, n=8, n=12, n=9, n=8$, according to the above list of agents).

\section{III.4. Open-field test}

The effects of valproate and the KYNA analogue, which have been found to prolong the survival of N171-82Q tg animals significantly, were also tested on low locomotor activity and exploratory behaviour in the open-field paradigm. The treatment regime was the same as in the case of the survival time analysis, only the numbers of animals in the corresponding groups differing. We tested 3 groups of mice in the examinations of each compound: the control wt mice ( $n=8$ in both cases), the control N171-82Q tg mice ( $n=8$ in both cases) and the valproate- $(n=8)$ and the KYNA analogue-treated $(n=9)$ N171-82Q tg mice. We 
examined the spontaneous locomotor activity and the exploration activity of the mice once a week, $2 \mathrm{~h}$ after the treatment, on the same day each week. The tests were performed at the same time of day to avoid possible changes due to the diurnal rhythm. Each mouse was placed at the centre of a box $(48 \times 48 \times 40 \mathrm{~cm})$ and its behaviour was recorded for 5 min with the aid of Conducta 1.0 software (Experimetria Ltd., Budapest, Hungary). The ambulation distance, the duration of the lack of locomotion (local time), the duration of immobility (immobility time) and the number of rearings (rearing count) were evaluated for 9 weeks (between 7 and 15 weeks of age). After calculation of the averages for the first, second and third 3 weeks in each group, the 3 experimental groups were compared.

\section{III.5. Testing for possible behavioural side-effects of valproate and the KYNA analogue in wt} mice

To search for possible behavioural side-effects of valproate and the KYNA analogue, another population of wt $\mathrm{B} 6 \mathrm{C} 3 \mathrm{~F} 1$ mice was tested ( $n=8$ in each group). In one experiment, the mice received either valproate or saline, and in the other experiment the KYNA analogue or $0.1 \mathrm{M}$ PBS for 9 weeks according to the treatment regime detailed above.

First, open-field tests were performed once a week, similarly $2 \mathrm{~h}$ after the daily treatment, and were evaluated in the same way as in the former experiment.

Secondly, in order to examine the effects of KYNA analogue treatment on anxiety-like behaviour, we applied the elevated plus maze paradigm in the last week of treatment. $2 \mathrm{~h}$ after the ip injection, the mice were placed in the central area of the device (height: $40 \mathrm{~cm}$; length of arms: $30 \mathrm{~cm}$; width of arms: $10 \mathrm{~cm}$; height of walls: $10 \mathrm{~cm}$ ), facing an open arm opposite the 2 observers. The numbers of open and closed arm entries and the times spent in these arms were recorded for $5 \mathrm{~min}$.

Thirdly, we applied the conventional stereotypy rating scale (SRS) method (McNamara et al., 2003), also in the last week of treatment, $2 \mathrm{~h}$ after the daily injection, to examine the possible stereotypic behaviour-inducing effects of the KYNA analogue. The animals were removed from their home cages and placed individually in a clean cage for observation. The animals were assessed over a 30 -s period and were scored in accordance with the nature of their activity: $0=$ asleep or inactive; 1 = episodes of normal activity; $2=$ discontinuous activity with bursts of prominent sniffing or rearing; $3=$ continuous stereotyped 
activity, such as sniffing or rearing along a fixed path; $4=$ stereotyped sniffing or rearing fixated in one location; $5=$ stereotyped behaviour with bursts of licking or gnawing; and $6=$ continuous licking or gnawing. The examination was repeated on a further 2 occasions at 20min intervals, and the scores were averaged.

\section{III.6. High-performance liquid chromatography (HPLC) measurements}

In week 9 of treatment, the valproatetreated and control wt mice were decapitated and the brains were rapidly removed and placed on an ice-cooled plate for dissection of the striatum. After dissection, the samples were stored at $-70{ }^{\circ} \mathrm{C}$ until measurements. The striata were weighed and were then manually homogenized in an ice-cooled solution $(250$ $\mu \mathrm{l})$ comprising perchloric acid $(7.2 \mu \mathrm{l} ; 70 \%$ $\mathrm{wt} / \mathrm{wt})$, sodium metabisulfite $(1 \mu \mathrm{l} ; 0.1 \mathrm{M})$, disodium ethylenediaminetetraacetate $(1.25$ $\mu \mathrm{l} ; 0.1 \mathrm{M})$ and distilled water $(240.55 \mu \mathrm{l})$ in a homogenization tube for $1 \mathrm{~min}$. The contents of the homogenization tube were quantitatively washed into a test tube with the

(a)

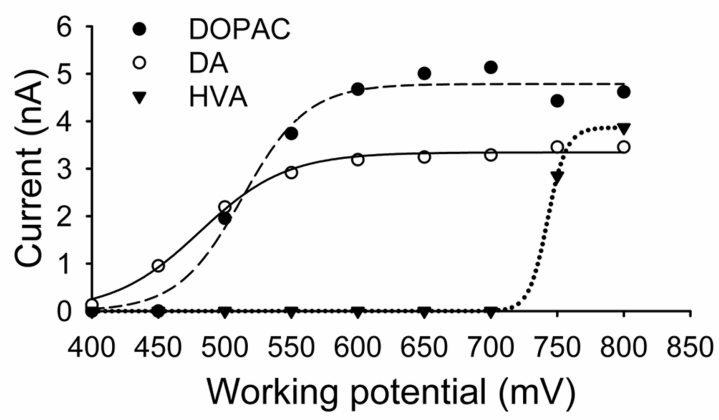

(b)

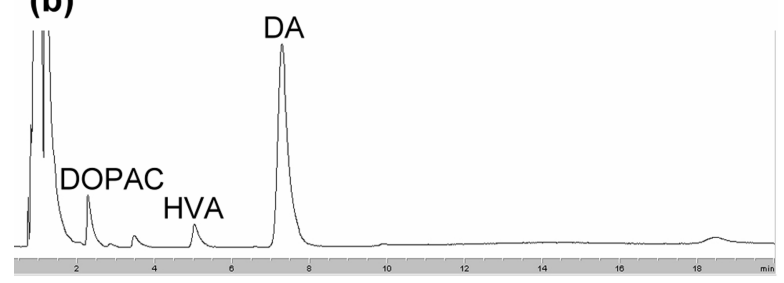

Figure 4. The characteristic current $\square$ voltage curves for DA, DOPAC and HVA (a) and a representative chromatogram achieved by HPLC measurement with electrochemical detection. used solution to give a final volume of $2 \mathrm{ml}$, which was centrifuged at $4,000 \mathrm{~g}$ for $30 \mathrm{~min}$ at $4{ }^{\circ} \mathrm{C}$. From the supernatant, $250 \mu \mathrm{l}$ was transferred to a test vial, and DA and its metabolites, 3,4-dihydroxyphenylacetic acid (DOPAC) and homovanillic acid (HVA), were analysed by reversed-phase chromatography, using an Agilent 1100 HPLC system (Agilent Technologies, Santa Clara, CA, USA) combined with a Model 105 electrochemical detector (Precision Instruments, Marseille, France) under isocratic conditions. In brief, the working potential of the detector was set at +750 $\mathrm{mV}$, using a glassy carbon electrode and an $\mathrm{Ag} / \mathrm{AgCl}$ reference electrode, after recording the current-voltage curve for each compound (Fig. 4a). The mobile phase containing sodium dihydrogenphosphate $(75 \mathrm{mM})$, sodium octylsulfate $(2.8 \mathrm{mM})$ and 
disodium ethylenediaminetetraacetate $(50 \mu \mathrm{M})$ was supplemented with acetonitrile $(10 \%$ $\mathrm{vol} / \mathrm{vol})$ and the $\mathrm{pH}$ was adjusted to 2.8 with phosphoric acid $(85 \% \mathrm{wt} / \mathrm{wt})$. The mobile phase was delivered at a rate of $1 \mathrm{ml} / \mathrm{min}$ at $40^{\circ} \mathrm{C}$ onto the reversed-phase column (HR-80 C18, 80 x $4.6 \mathrm{~mm}, 3 \mu \mathrm{m}$ particle size; ESA Biosciences, Chelmsford, MA, USA) after passage through a pre-column (Hypersil ODS, $20 \times 2.1 \mathrm{~mm}, 5 \mu \mathrm{m}$ particle size; Agilent Technologies, Santa Clara, CA, USA). Ten-microlitre aliquots were injected by the autosampler with the cooling module set at $4{ }^{\circ} \mathrm{C}$.

The signals captured by the Model 105 electrochemical detector were converted by an Agilent 35900E dual-channel interface and the chromatograms (for a representative chromatogram, see Fig. 4b) were evaluated by ChemStation Rev.1.10.02 software (Agilent Technologies, Santa Clara, CA, USA).

\section{III.7. Anatomy and immunohistochemistry}

The body weights of the mice treated with the KYNA analogue were measured once a week, on the same day each week, at the same time of a day, from 7 weeks of age. When the animals reached 16 weeks of age, they were deeply anesthetized with isoflurane (Forane ${ }^{\circledR}$; Abott Laboratories Hungary Ltd., Budapest, Hungary) and perfused transcardially with $0.9 \%$ (wt/vol) $\mathrm{NaCl}$ solution, followed by $4 \%$ (wt/vol) paraformaldehyde. The perfused brains were removed, weighed, post-fixed with $4 \%(\mathrm{wt} / \mathrm{vol})$ paraformaldehyde for $24 \mathrm{~h}$ and transferred into $0.1 \mathrm{M}$ phosphate buffer (PB; pH 7.4) containing 0.05\% (wt/vol) azide. Blocks containing the whole striatum were dissected ( 7 brains were processed in each group) and incised in the middle so that the hemispheres could be handled separately. The whole striatum was sectioned on a vibratome at $60-\mu \mathrm{m}$ thickness and the sections were collected in a systematic random fashion in 7 vials. In this way, the sections with a distance of $420 \mu \mathrm{m}$ (between the upper surfaces) were put into the same glass vials. We therefore investigated the striatum, which extends from bregma $1420 \mu \mathrm{m}$ to bregma $-2355 \mu \mathrm{m}(3775 \mu \mathrm{m})$ according to the onlineavailable Allen Brain Atlas: Mouse Brain, throughout its whole extent [multiplying the distance of $420 \mu \mathrm{m}$ between the upper surfaces of sections by the number of sections $(n=9$ or 8 depending on the presence of atrophy); the result was 3360-3780 $\mu \mathrm{m}]$. The sampling was followed by washing in $0.1 \mathrm{M}$ PB and incubation in 10 and 30\% (wt/vol) sucrose for cryoprotection. After freeze-thawing, the sections of the left hemisphere were washed 
repeatedly in $0.1 \mathrm{M} \mathrm{PB}$, and processed for immunostaining. Following rinsing in $0.05 \mathrm{M}$ Trisbuffered saline (TBS; $\mathrm{pH} 7.4$ ), the free-floating sections were incubated in $1 \%(\mathrm{wt} / \mathrm{wt})$ hydrogen peroxide in $0.05 \mathrm{M}$ TBS to suppress endogenous peroxidase activity. After washing in $0.05 \mathrm{M}$ TBS and incubation in 2\% ( $\mathrm{vol} / \mathrm{vol}$ ) normal horse serum (Vector Laboratories Inc., Burlingame, CA, USA) diluted in 0.05 M TBS, sections were incubated in solutions of either anti-NeuN (clone 60; mouse monoclonal antibody; catalogue number MAB377; lot number LV1616015; 1:5,000; Millipore, Bilerica, MA, USA) or anti-huntingtin (clone mEM48, recognizing the first 256 amino acids of the human huntingtin protein; mouse monoclonal antibody; catalogue number MAB5374; lot number LV1541616; 1:200; Millipore, Bilerica, MA, USA) primary antibodies diluted in $0.05 \mathrm{M}$ TBS for $35 \mathrm{~h}$ at room temperature. After subsequent extensive washes in $0.05 \mathrm{M}$ TBS, the sections were incubated overnight at $4{ }^{\circ} \mathrm{C}$ with biotinylated donkey anti-mouse secondary antibody (1:1,000; Jackson ImmunoResearch Laboratories Inc., West Grove, PA, USA), diluted in 0.05 M TBS, followed by avidinbiotinylated horseradish peroxidase complex (Elite ABC, 1:333; Vector Laboratories Inc., Burlingame, CA, USA), diluted in $0.05 \mathrm{M}$ TBS for $3 \mathrm{~h}$ at room temperature. The immunoperoxidase reaction was developed by using 3,3'-diaminobenzidine (Sigma-Aldrich Hungary Ltd., Budapest, Hungary) as a chromogen. The sections were treated with osmium tetroxide in $\mathrm{PB}$, then dehydrated in an ascending alcohol series and acetonitrile, and embedded in Durcupan (ACM; Fluka, Buchs, Schwitzerland).

To present representative sets of whole brain slice images from each group for demonstrative purposes, brains ( 1 from each group) were cut into frozen $30-\mu \mathrm{m}$-thick coronal sections from $450 \mu \mathrm{m}$ anterior to the bregma. Twelve sets consisting of 4 sections each, 360 $\mu \mathrm{m}$ apart, were collected in wells containing 0.1 M PBS. One set of brain slices from each group was then mounted onto the slides from distilled water and, after drying, the slides were stained with $1 \%(\mathrm{wt} / \mathrm{vol})$ cresyl violet, followed by dehydration in an ascending alcohol series and xylene, and coverslipped through the use of DPX mounting medium. 
III.8. Stereology

We used the unbiased design-based stereology method (reviewed by West, 2002) on the Durcupan-embedded sections to estimate the number and size of the neurons in the striatum. The group means of the mounted section thicknesses did not differ significantly either in anti-NeuN (wt: $25.4 \pm 0.3 \mu \mathrm{m}$; tg: $25.0 \pm 0.2 \mu \mathrm{m}$; $\operatorname{tg}$ treated: $25.3 \pm 0.3 \mu \mathrm{m}$ ) or in anti-huntingtin (tg: $24.8 \pm 0.2 \mu \mathrm{m}$; tg treated: $25.1 \pm 0.1 \mu \mathrm{m})$ immunostained sections. The complete penetration of the antibodies was verified by using the z-axis histograms in the sections, and the osmication procedure ensured the clear identification of cell and nucleus contours, confirming that these samples were suitable for accurate stereological analyses (Fig. 5a-f). The contours of the striatum were traced in each serial section ( $n=8-9)$, using a 10x objective of a Zeiss Axioskop 2 (Carl Zeiss MicroImaging Ltd., Göttingen, Germany) and the Stereo Investigator software (MBF Bioscience, Williston, VT, USA). Subsequently, we utilized a 100x objective with oil immersion (numeric aperture: 1.4) for

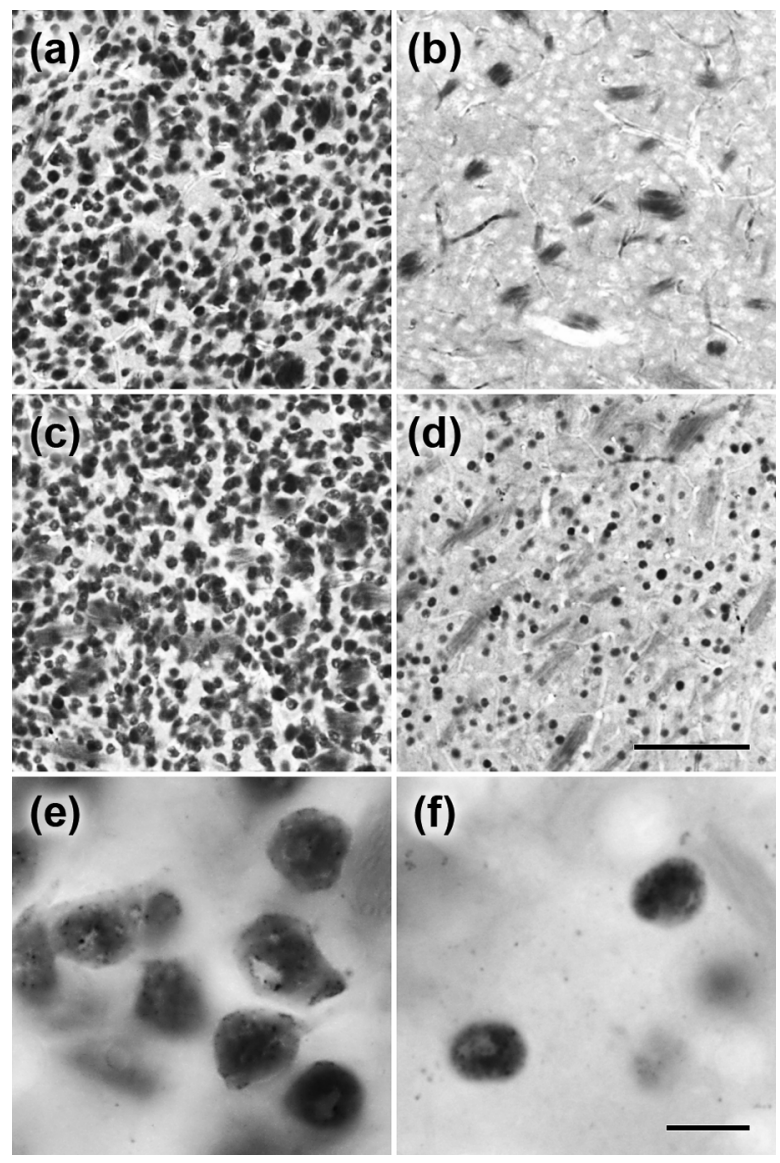

Figure 5. Low- and high-magnification photomicrographs of the striata from 16-weekold wt and N171-82Q tg mice. Such representative light micrographs do not show any obvious difference in the number of antiNeuN-stained neurons between the wt (a) and N171-82Q tg animals (c). As concerns the $\mathrm{EM} \mathrm{H}^{+}$immunoreactivity, no labelled nucleus was observed in the wt mice (b), whereas cells could readily be observed in the N171-82Q tg animals (d). Stereological investigations at high magnification clearly revealed the contours of anti-NeuN-stained cells (e) and $\mathrm{EM}^{+}{ }^{+}$nuclei (f) (scale bar: a-d: $100 \mu \mathrm{m}, \mathrm{e}-\mathrm{f:}: 10 \mu \mathrm{m}$ ). quantification of the anti-NeuN-stained neurons (grid size: $500 \times 500 \mu \mathrm{m}$ ) and antihuntingtin-stained nuclei (grid size: $350 \times 350 \mu \mathrm{m}$ ) with the optical fractionator method, applying a counting frame of $40 \times 40 \mu \mathrm{m}$. As a counting rule, we made use of the unbiased counting brick rule, with a brick height of $15 \mu \mathrm{m}$ and guard zones of $4 \mu \mathrm{m}$. On average, we 
counted $\sim 623 \pm 12$ anti-NeuN-stained neurons and $\sim 267 \pm 49$ anti-huntingtin-stained nuclei in each animal in order to estimate the total number of immunoreactive neurons in its striatum, and calculated the radii of $\sim 87 \pm 2$ neurons per mouse in order to estimate the average volume of its neurons in its striatum.

For estimation of the striatal volume $\left(\mathrm{V}_{\text {str }}\right)$, we used the following formula:

$$
\mathrm{V}_{\mathrm{str}}=\sum_{\mathrm{i}=1}^{\mathrm{n}} \mathrm{A}_{\mathrm{i}} \times 1 / \mathrm{ssf} \times 60 \times 2
$$

where $A_{i}$ is the area of the left striatum in the consecutive sections and ssf is the section sampling fraction, 60 is the original section thickness and the product is multiplied by 2 to calculate $\mathrm{V}_{\text {str }}$ for the 2 hemispheres.

The total numbers of anti-NeuN-stained neurons and anti-huntingtin-stained nuclei in the whole striatum were estimated by using the optical fractionator method and the following formula:

$N=($ total number of objects counted in the left striatum) $\times 1 /$ ssf $\times 1 /$ asf $\times 1 /$ hsf $\times 2$ where ssf is the section sampling fraction, asf is the area sampling fraction and hsf is the height sampling fraction. The product is likewise multiplied by 2 to calculate the total number of cells in the whole striatum of the 2 hemispheres.

The isotropic orientation of the striatal neurons allowed the use of the nucleator probe in our samples to estimate neuronal volumes $\left(\mathrm{V}_{\mathrm{N}}\right.$; Schmitz et al., 1999). Here, the systematic random selection of neurons was ensured by the selection of the first neurons coming into focus in each counting brick. The Stereo Investigator software calculated $V_{N}$ via the following formula, where $r$ is the average radius of a neuron:

$$
\mathrm{V}_{\mathrm{N}}=(4 \pi / 3) \mathrm{x} \mathrm{r}^{3}
$$

\section{III.9. Statistics}

All statistical analyses were performed with the help of the SPSS Statistics 17.0 software. Survival data were analysed by using Kaplan-Meier survival curves and the MantelCox log rank test. In the cases of behavioural tests, HPLC measurements and anatomical analyses, we first checked the distribution of data populations with the Shapiro-Wilk W test, and also performed the Levene test for analysis of the homogeneity of variances. If the data showed a non-Gaussian distribution, or equal variances were not assumed, we used non- 
parametric statistics: the Mann-Whitney $U$ test when 2 groups were compared, and the Kruskal-Wallis test when there were more than 2 groups. If the data were distributed normally and equal variances were assumed, we used parametric statistics: 2 groups were compared via the independent $t$ test, and multiple groups of data were compared by using repeated or oneway measures of analysis of variance (ANOVA) followed by Fischer's least significant difference post hoc test comparison. The null hypothesis was rejected when the $p$ level was < 0.05 , and in such cases the differences were considered significant. In the event of Gaussian or of non-Gaussian distributions, data were plotted as means ( \pm standard error of mean (SEM)) or medians (and interquartile range) in the graphs, respectively.

\section{Results}

\section{IV.1. Survival}

Valproate, administered ip at a dose of $100 \mathrm{mg} / \mathrm{kg}$, increased the mean survival time of the N171-82Q tg mice significantly, from $109.8 \pm 9.7$ days to $144.3 \pm 7.9$ days, i.e. by $31.4 \%$ [ $p=0.034$; Fig. 6a]. Similarly, the KYNA analogue, administered ip at a dose of $100 \mathrm{mg} / \mathrm{kg}$, also increased the mean survival time of the N171-82Q tg mice significantly, from $111.3 \pm$ 6.6 days to $145.5 \pm 12.0$ days, i.e. by $30.7 \%$ [ $p=0.016$; Fig. 6b]. In contrast, the ip administration of L-KYN (dose: $100 \mathrm{mg} / \mathrm{kg}$; survival time of treated animals: $116.2 \pm 4.4$ days; survival time of control animals: $111.3 \pm 6.6$ days; percentage improvement: 4.4\%; Fig. 6c), L-carnosine (dose: $200 \mathrm{mg} / \mathrm{kg}$; survival time of treated animals: $134.2 \pm 6.2$ days; survival time of control animals: $122.5 \pm 5.4$ days; percentage improvement: 9.6\%; Fig. 6d), pioglitazone (dose: $5 \mathrm{mg} / \mathrm{kg}$; survival time of treated animals: $109.7 \pm 9.7$ days; survival time of control animals: $117.1 \pm 8.0$ days; percentage improvement: $-6.3 \%$; Fig. 6e) or BZS1514 (dose: $20 \mathrm{mg} / \mathrm{kg}$; survival time of treated animals: $137.9 \pm 9.4$ days; survival time of control animals: $124.8 \pm 8.2$ days; percentage improvement: 10.5\%; Fig. $6 f$ ) did not prolong the survival of N171-82Q tg mice significantly. The results of survival analyses are presented in table 1 . 
Table 1. Percentage improvement of survival duration after treatment of N171-82Q tg mice with the test compounds.

\begin{tabular}{lcc}
\hline Group pairs & $\begin{array}{c}\text { Survival duration } \\
\text { (days; mean } \pm \text { SEM) }\end{array}$ & Percentage improvement \\
\hline Control & $109.8 \pm 9.7$ & $31.4 \%$ \\
Valproate & $144.3 \pm 7.9$ & $30.7 \%$ \\
\hline Control & $111.3 \pm 6.6$ & \\
KYNA analogue & $145.5 \pm 12.0$ & $4.4 \%$ \\
\hline Control & $111.3 \pm 6.6$ & $9.6 \%$ \\
L-KYN & $116.2 \pm 4.4$ & \\
\hline Control & $122.5 \pm 5.4$ & $-6.3 \%$ \\
L-Carnosine & $134.2 \pm 6.2$ & $10.5 \%$ \\
\hline Control & $117.1 \pm 8.0$ & \\
\hline Pioglitazone & $109.7 \pm 9.7$ & \\
\hline Control & $124.8 \pm 8.2$ & \\
\hline BZS1514 & $137.9 \pm 9.4$ & \\
\hline
\end{tabular}


(a)
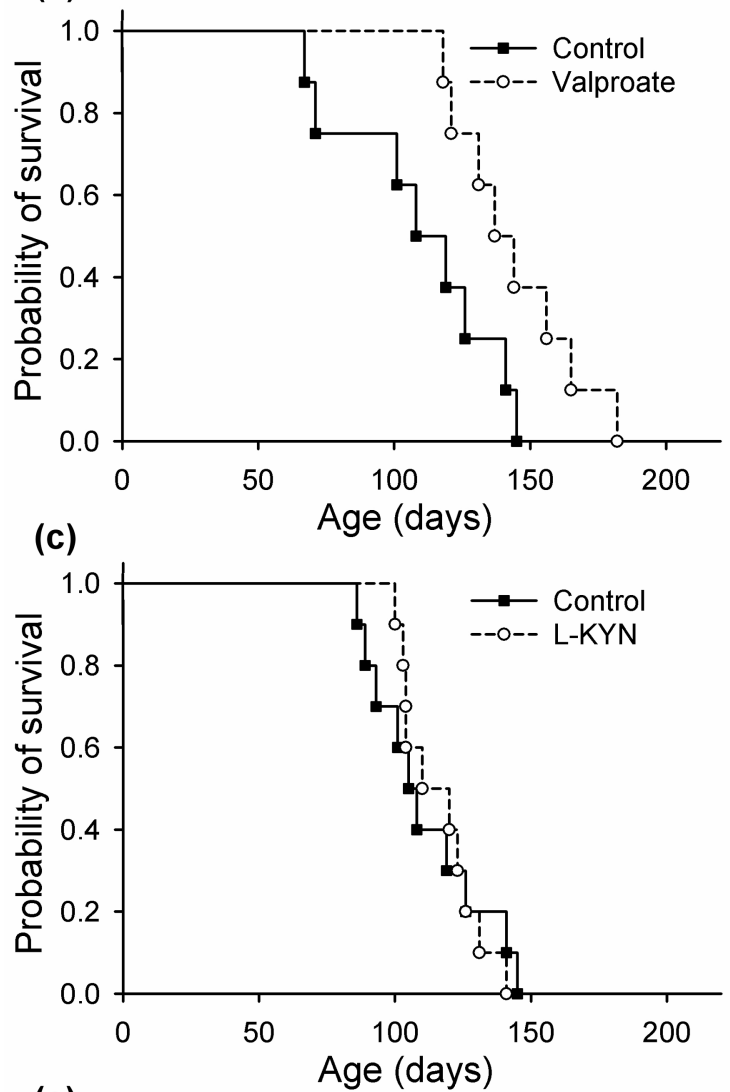

(e)

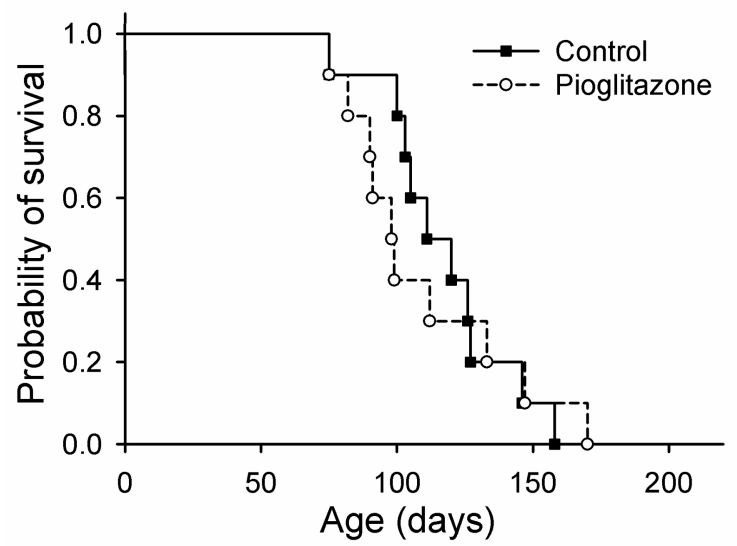

(b)
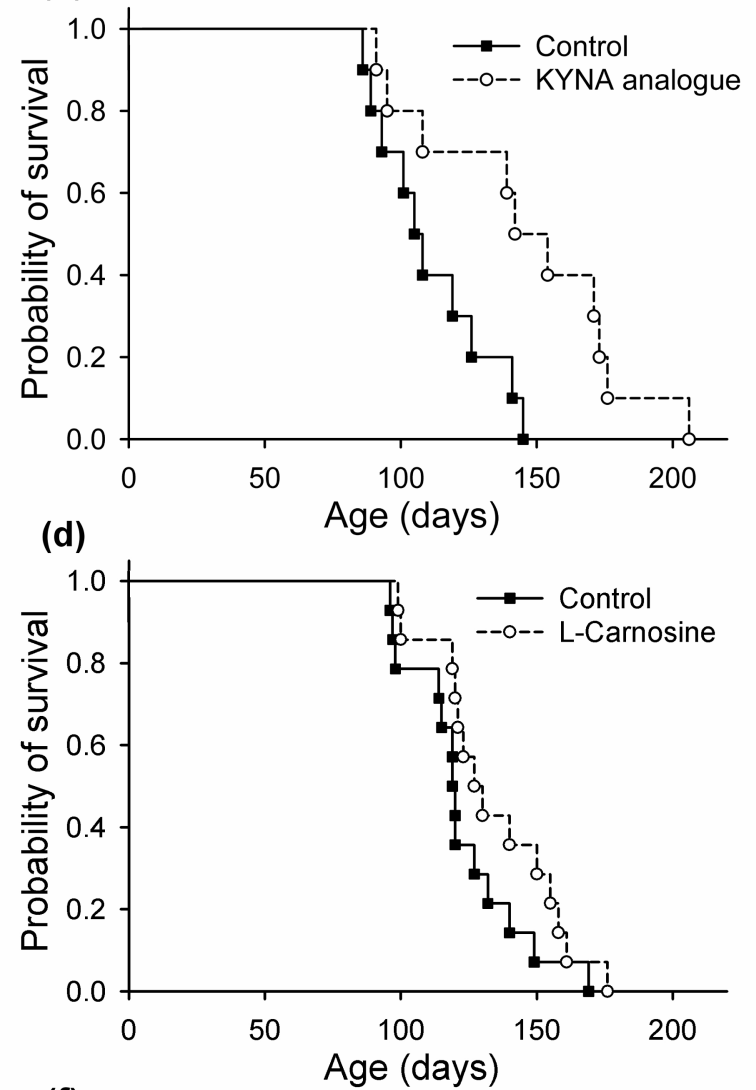

(f)

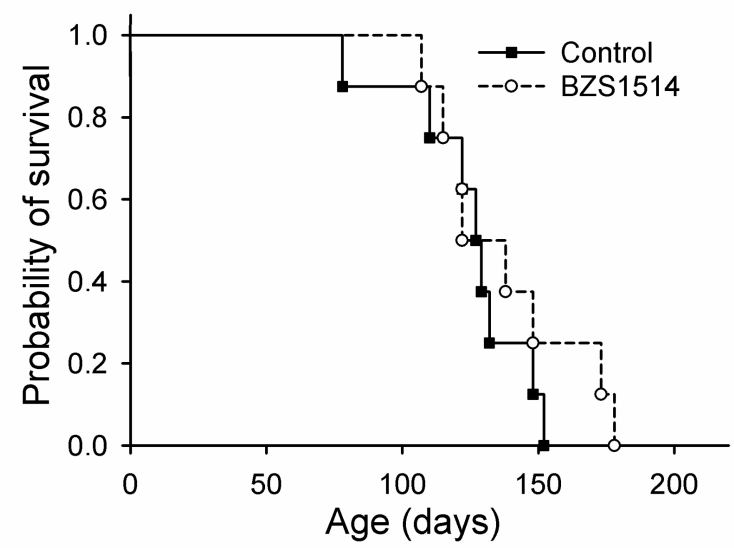

Figure 6. Kaplan-Meier survival curves of the 6 groups of N171-82Q tg mice treated with test compounds and those of the corresponding control groups. The treatment with valproate (a) or the KYNA analogue (b) significantly increased the survival time relative to the controls $(p<0.05$, MantelCox log rank test), whereas the treatment with L-KYN (c), L-carnosine (d), pioglitazone (e) or BZS1514 (f) did not exert any significant amelioration (valproate-treated N171-82Q tg mice and control N17182Q tg mice: both $n=8$; KYNA analogue-treated N171-82Q tg mice and control N171-82Q tg mice: both $n=10$; L-KYN-treated N171-82Q tg mice and control N171-82Q tg mice: both $n=10$; L-carnosinetreated N171-82Q tg mice and control N171-82Q tg mice: both $n=14$; pioglitazone-treated N171-82Q tg mice and control N171-82Q tg mice: both $n=10 ;$ BZS1514-treated N171-82Q tg mice and control N17182Q tg mice: both $n=8$ ). 

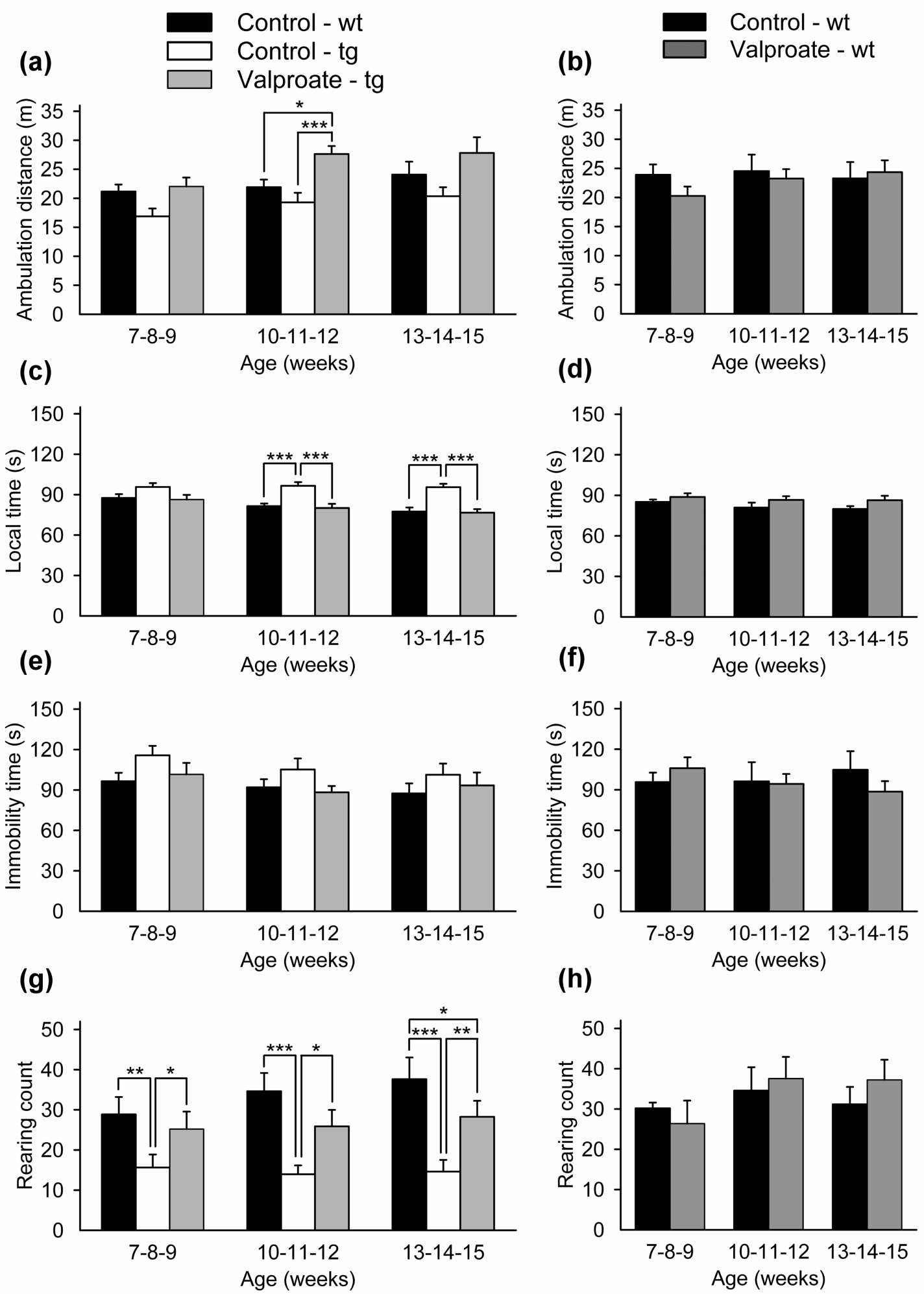

Figure 7. The effects of valproate on the examined behavioural parameters in N171-82Q tg and wt mice. Valproate significantly ameliorated the characteristic hypolocomotion in the N171-82Q tg mice, examined via the ambulation distance (a) and local time (c) in open-field tests, while the immobility time data (e) did not reveal any significant difference between the groups. The treatment with valproate did not exert any effect either on the ambulation distance (b), or on the local time (d) or on the immobility time (f) in wt mice. With regard to the exploratory activity, valproate significantly increased the low rearing count characteristic of the $N 171-82 Q$ tg animals $(g)$, whereas it did not exert any significant effect in the wt mice (h) (wt mice: $n=8$; N171-82Q tg control mice: weeks 7-9: $n=8$, weeks 10-15: $n=7$; N171-82Q tg treated mice: weeks 7-15: $n=8$; data are means + SEM; $* p<0.05, * * p<0.01, * * * p<$ 0.001). 

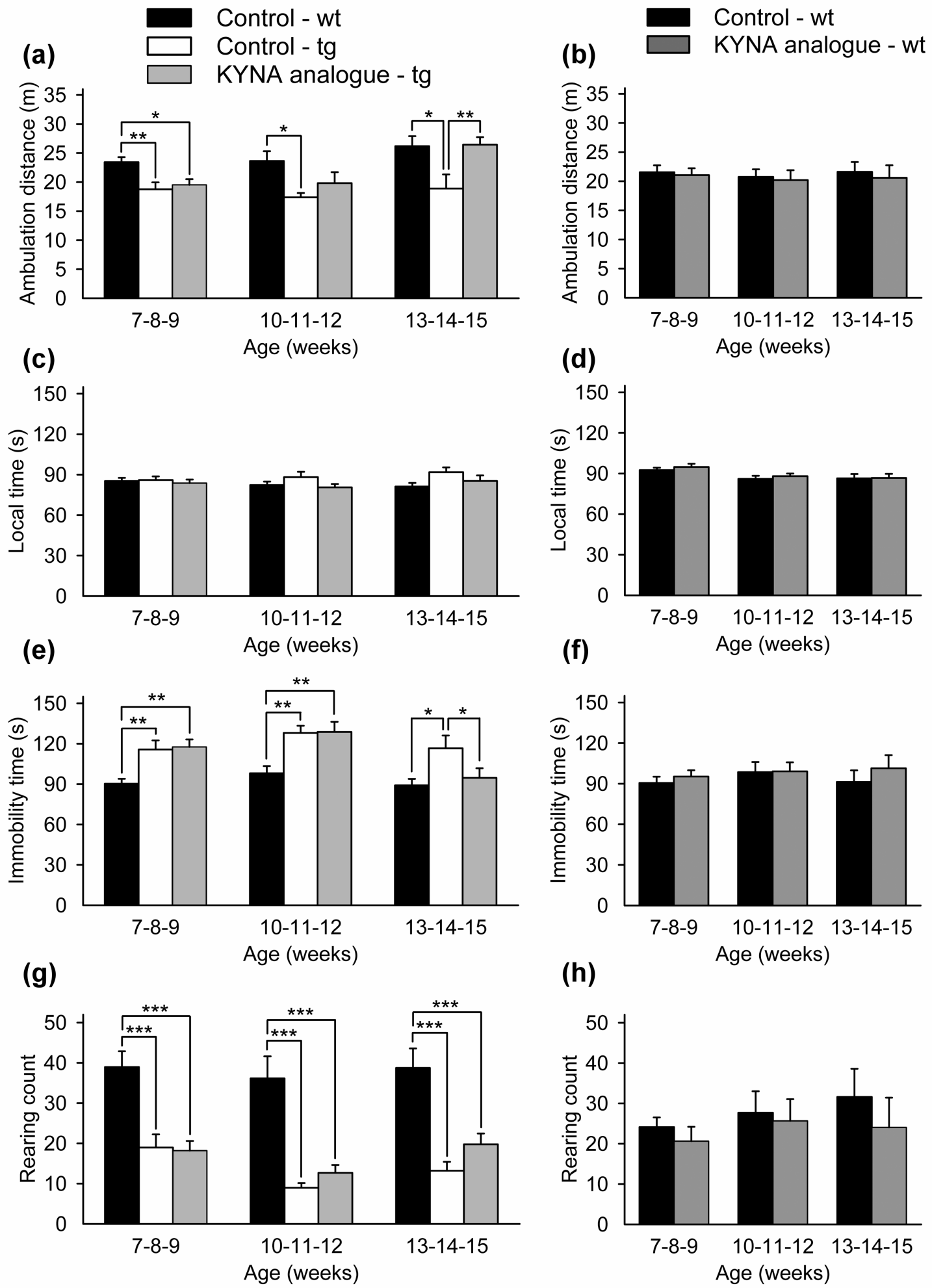

Figure 8. The effects of the KYNA analogue on the examined behavioural parameters in N171-82Q tg and wt mice. The analogue significantly ameliorated the characteristic hypolocomotion in the N171-82Q tg mice, examined via the ambulation distance (a) and immobility time (e) in open-field tests, while the local time data (c) did not reveal any significant difference between the groups. The treatment with the KYNA analogue did not exert any effect either on the ambulation distance (b), or on the local time (d) or immobility time (f) in the wt mice. With regard to the exploratory activity, the analogue did not influence the low rearing count characteristic of the N171-82Q tg animals (g), and did not exert any significant effect in the wt mice either (h) (wt mice: $n=8$; N171-82Q tg control mice: weeks 7-12: $n=8$, weeks 13-15: $n=7$; N171-82Q tg treated mice: weeks 7-12: $n=9$, weeks 13-15: $n=8$; data are means + SEM; $\left.{ }^{*} p<0.05, * * p<0.01, * * * p<0.001\right)$. 


\section{IV.2. Behavioural tests}

Through use of the open-field paradigm, we tested the valproate- and the KYNA analogue-treated N171-82Q tg mice together with their corresponding control wt mice and the N171-82Q tg mice. We first assessed the locomotor activity of these animals by measuring their ambulation distance, local time and immobility time in the open-field during the test period for 9 consecutive weeks. During the tests in the first 3 weeks, the N171-82Q tg mice covered a $20.5 \%$ and $19.9 \%$ shorter distance than the wt mice in the 2 experiments, respectively. The ANOVA revealed no significant difference in the experimental valproate assessment $\left[\mathrm{F}_{(2,21)}=3.372, p=0.054\right.$; Fig. 7a], but in the experimental KYNA analogue assessment this difference did prove significant $\left[\mathrm{F}_{(2,22)}=5.795, p=0.01\right.$; post hoc test: $p=$ 0.0046; Fig. 8a]. Although valproate had already exerted a visible amelioration at that time, the KYNA analogue clearly had no effect. The measurements of local time (Figs. 7c and 8c) and immobility time (Figs. 7e and 8e) showed identical results with the corresponding ambulation distance data in both experiments. During the second 3 weeks, valproate significantly increased the ambulation distance $\left[\mathrm{F}_{(2,20)}=8.716, p=0.002\right.$; post hoc test: $p=$ 0.00057; Fig. 7a $]$ and significantly decreased the local time $\left[\mathrm{F}_{(2,20)}=11.63, p=0.00045\right.$; post hoc test: $p=0.00029$; Fig. $7 \mathrm{c}]$ of the N171-82Q tg mice as compared with those of the untreated tg animals, while the immobility time data did not prove any significant differences between the groups. The increase in ambulation distance was also significant as compared with the wt mice [post hoc test: $p=0.014$; Fig. 7a]. As regards the treatment with the KYNA analogue, we could already detect some positive changes in the behaviour of the treated N171-82Q tg mice: as concerns the ambulation distance data, a significant difference could no longer be detected between the wt and the treated N171-82Q tg mice (Fig. 8a). However, there was still a significant increase in immobility time in the treated N171-82Q tg mice as compared with the control wt animals $\left[\mathrm{F}_{(2,22)}=7.569, p=0.003\right.$; post hoc test: $p=0.002$; Fig. $8 \mathrm{e}$. The local time data did not prove any significant differences between the groups (Fig. 8c). During the third 3 weeks, the differences in ambulation distance were no longer significant in the experiment assessing the effects of valproate (Fig. 7a), probably due to an increase in the standard deviation. However, the significant difference in local time $\left[\mathrm{F}_{(2,20)}=\right.$ 15.71, $p=0.00045$; post hoc test: $p=0.000067]$ still remained between the valproate-treated and untreated N171-82Q tg animals (Fig. 8c). The treatment wit the KYNA analogue restored 
the locomotor activity of the treated N171-82Q tg mice to the wt level and their performance became significantly different from that of the non-treated N171-82Q tg mice group both in ambulation distance $\left[\mathrm{F}_{(2,20)}=5.217, p=0.015\right.$; post hoc test: $p=0.009$; Fig. 8a], and in immobility time $\left[\mathrm{F}_{(2,20)}=3.916, p=0.037\right.$; post hoc test: $p=0.046$; Fig. 8e]. In the independent control experiments, neither valproate (Fig. 7b,d,f) nor the KYNA analogue (Fig. $8 b, d, f)$ themselves influenced the spontaneous locomotor activity of the wt mice.

In addition to the examination of spontaneous locomotor activity, we also tested the exploratory behaviour of the mice. We found that, whereas the N171-82Q tg mice reared significantly less than the wt mice $\left[\mathrm{by} \sim 65 \% ; \mathrm{F}_{(2,22)}=14.08, p=0.000153\right.$; post hoc test: $p=$ $0.000062]$, the treatment with valproate significantly increased the number of rearings $\left[\mathrm{F}_{(2,21)}\right.$ $=5.005, p=0.017$; post hoc test: $p=0.018]$, the increase remaining throughout the examination period (Fig. 7g). The KYNA analogue did not change this behaviour significantly, although the difference between the treated and the non-treated mice did become larger by the end of the third 3 weeks (Fig. 8g). In the independent control experiments, neither valproate (Fig. 7h) nor the KYNA analogue (Fig. 8h) themselves influenced the exploratory activity of the wt mice.

The results of the elevated plus maze test at 15 weeks of age in the wt animals showed that there was no significant difference between the KYNA analogue-treated and untreated groups as concerns the percentage of time spent in the closed arms (Fig. 9a) or the number of closed arm entries (data not shown). The results on the SRS demonstrated that the treatment with the KYNA analogue did not induce the

stereotypic behaviour in the wt mice (Fig. 9b).

Figure 9. The examination of the possible influence of the KYNA analogue on anxiety-related behaviour and stereotypy in wt mice. The results of the elevated plus maze test (a), examined via the percentage of time spent in the closed arms, and the results of the SRS (b) did not reveal any significant difference between the analogue-treated and control wt animals $(n=8$ in both groups; data are means + SEM (a) or medians and interquartile range (b)). (a)

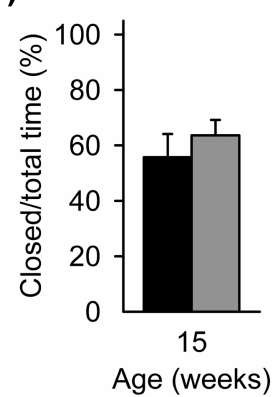

(b)

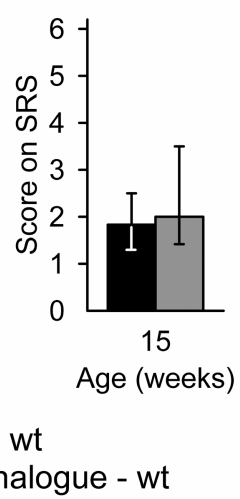




\section{IV.3. HPLC measurements}

Following its ip administration in a dose of $100 \mathrm{mg} / \mathrm{kg}$ on 5 days per week for 9

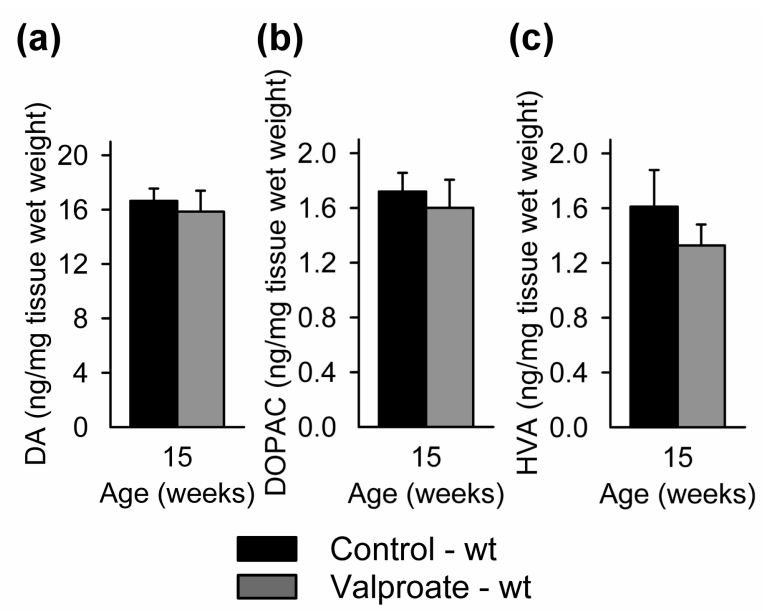
weeks, valproate did not induce significant changes in the striatal DA (Fig. 10a), DOPAC (Fig. 10b) or HVA (Fig. 10c) levels.

Figure 10. Striatal DA, DOPAC and HVA concentrations of valproate-treated wt mice after 9 weeks of treatment. Valproate treatment did not significantly influence the striatal level of DA (a), or DOPAC (b) or HVA (c) as compared with the untreated wt mice ( $n=8$; data are means + S.E.M.).

\section{IV.4. Body weight and neuroanatomical changes}

The average body weight of the wt control animals increased continuously until around 14 weeks of age, whereas no increase in body weight was detected in the case of the N171-82Q tg mice after the age of 7 weeks, and hence the weights of the 2 groups were significantly different [repeated measures of ANOVA: $\mathrm{F}_{(9,108)}=20.27, p<0.000001$; Fig. 11a]. Our results revealed that the treatment with the KYNA analogue increased the body weight of the N171-82Q tg mice significantly [repeated measures of ANOVA: $F_{(9,108)}=3.961$, $p=0.00022$; Fig. 11a].

With regard to the CNS pathology, the brain weight of 16-week-old N171-82Q tg animals (432.2 $\pm 10.0 \mathrm{mg}$ ) was significantly lower, by $7.9 \%$, than that of the wt mice $[469.2 \pm$ $7.6 \mathrm{mg}$; independent $\mathrm{t}$ test: $p=0.012$ ], but that of the treated N171-82Q tg animals $(446.8 \pm$ $12.7 \mathrm{mg}$ ) was not significantly different (Fig. 11b). The stereologically measured $\mathrm{V}_{\text {str }}$ was also significantly lower [by $12.6 \% ; p=0.012$ ] in the N171-82Q tg animals $\left(17.4 \mathrm{~mm}^{3}\right.$, interquartile range: $14.6-17.7 \mathrm{~mm}^{3}$; for representative images see Fig. 12b1-4) than in the wt mice $\left(18.9 \mathrm{~mm}^{3}\right.$, interquartile range: $18.3-19.0 \mathrm{~mm}^{3}$; for representative images see Fig. 12a14). When the N171-82Q tg mice were treated with the KYNA analogue, their $\mathrm{V}_{\text {str }}$ was no longer different from that of the wt mice $\left(19.0 \mathrm{~mm}^{3}\right.$, interquartile range: $17.3-19.4 \mathrm{~mm}^{3}$; Fig. $11 \mathrm{c}$; for representative images see Fig. 12c1-4). 
Unbiased stereological methods did not indicate any significant difference in the number of neurons in the striatum of the control wt mice, the N171-82Q tg mice or the KYNA analogue-treated N171-82Q tg mice (Fig. 5a,c; Fig. 11d). However, we found that the average size of the neurons in the striatum of the N171-82Q $\operatorname{tg}$ animals $\left(663.4 \mu^{3}\right.$, interquartile range: 605.6-681.0 $\mu^{3}$ ) was lower by $14 \%$ [ $p=0.0022]$ than that for the wt mice $\left(739.0 \mu \mathrm{m}^{3}\right.$, interquartile range: 734.2 $802.1 \mu^{3}$; Fig. 11e). The treatment with the KYNA analogue completely prevented the development of atrophy of the neurons in the N171-82Q tg mice $\left(744.5 \mu^{3}\right.$, interquartile range: $716.2-787.4 \mu \mathrm{m}^{3}$ ), and the average size of these neurons was significantly different from that in the control non-treated N171-82Q tg animals [Kruskal-Wallis test: $\chi^{2}=13.01$, df $=2, p=0.0015$; Mann-Whitney $\mathrm{U}$ test: $p=$ 0.012; Fig. 11e].

The treatment with the KYNA

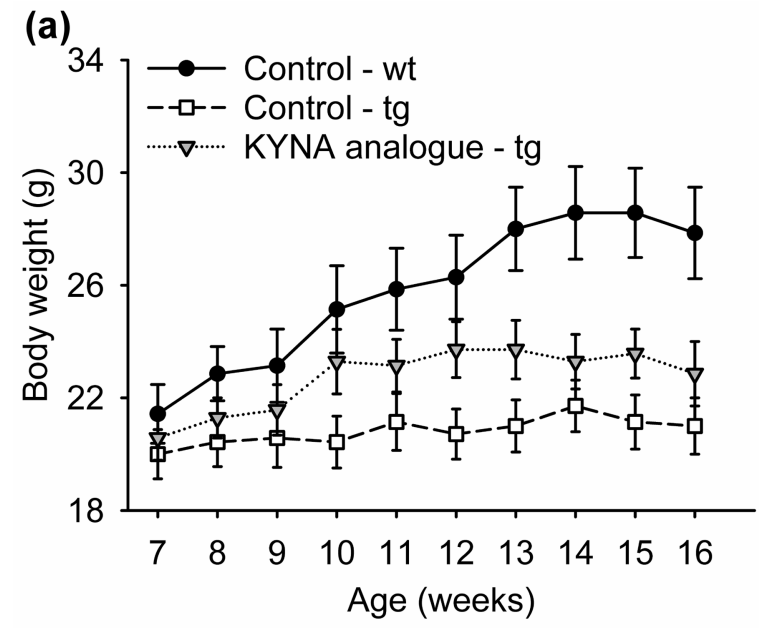

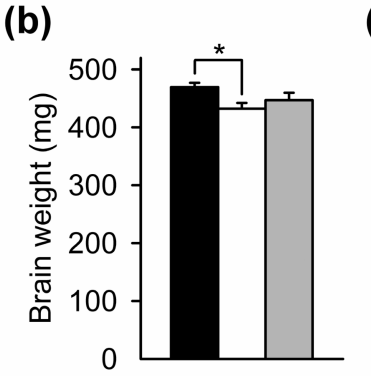

(b)

(d)

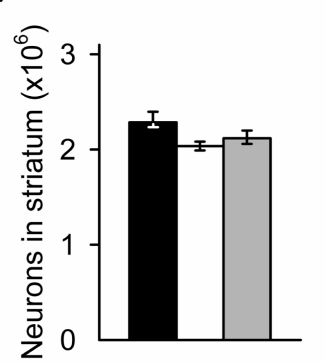

(c)

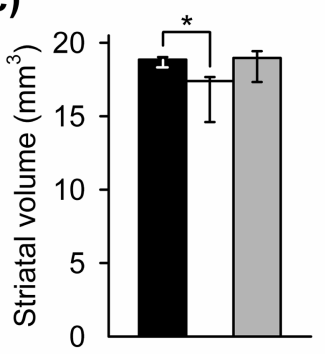

(e)

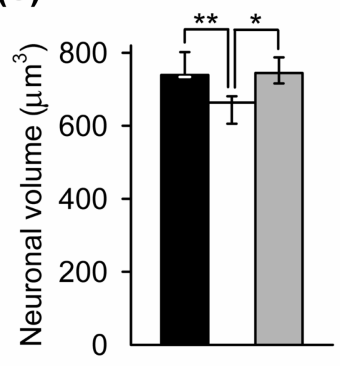

analogue did not induce a significant change in the percentage of anti-huntingtin immunoreactive $\left(\mathrm{EM} 48^{+}\right)$neurons in the striatum of the N171-82Q tg animals $(17.5 \%$

(f)

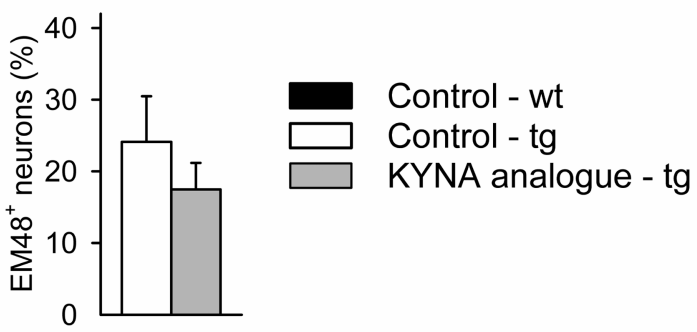

Figure 11. Effects of treatment with the KYNA analogue on the anatomical features of the mice. (a) A significant difference emerged between the body weights of $w t$ and N171-82Q tg animals with aging $(n=$ $7 ; p<0.000001$, repeated measures of ANOVA), which was significantly ameliorated by the treatment ( $p$ $<0.001$, repeated measures of ANOVA). The treatment abolished the significant differences in brain weight (b) and $V_{\text {str }}$ (c) between the wt and N171-82Q tg animals. Although the number of striatal neurons did not decrease significantly by 16 weeks of age (d), obvious neuronal atrophy could be observed in the N171-82Q tg animals, which was completely prevented by the treatment with the KYNA analogue (e). (f) As concerns the aggregation pathology, the treatment did not change the percentage of $\mathbf{E M}^{+} \mathbf{8}^{+}$neurons in the striatum significantly (data are means $+\operatorname{SEM}(\mathrm{a}, \mathrm{b}, \mathrm{f})$ or medians and interquartile range $(\mathrm{c}, \mathrm{d}, \mathrm{e}) ; * \boldsymbol{p}<0.05, * * p<0.01)$. 

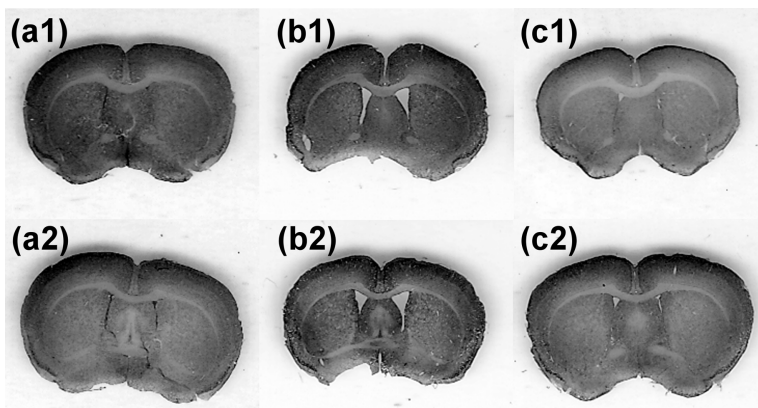

(b2)
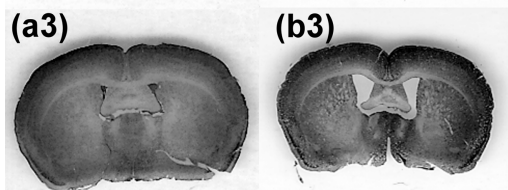

(c2)
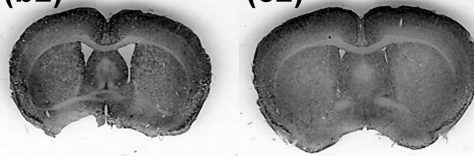

(a4)

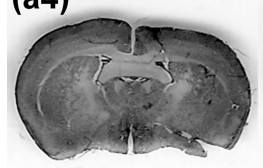

(b4)

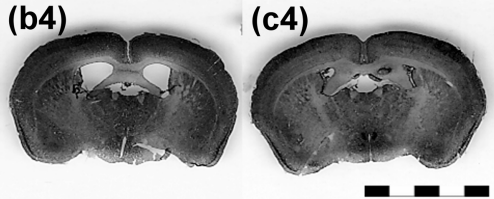

of the total neuron population) relative to the control N171-82Q tg animals $(24.1 \%$ of the total neuron population; Fig. 11f).

Figure 12. Macroscopic representative images of coronal sections from 16-week-old wt, N171-82Q tg and the KYNA analogue-treated N171-82Q tg mice. An excessive ventricular enlargement can be seen in the untreated N171-82Q tg animals (b1-4) relative to the wt mice (a1-4), which is totally prevented by the treatment with the KYNA analogue (c1-4) (scale bar: $5 \mathrm{~mm})$.

\section{Discussion}

Although it is known that a definite single mutation leads to the development of HD (the best example of trinucleotide repeat expansion disorders), it is unclear how this mutation actually results in disease pathogenesis. The pathomechanism must therefore be thoroughly explored, and effective new drugs with higher therapeutic value must be developed. Thus, the main aim of the research work directly related to this thesis was to find compounds, both well-known (with the possibility of a second medical use) and newly synthesized (with innovative purposes) agents of therapeutic potential in this devastating illness.

The logic of testing valproate emerged from its proved HDAC inhibitor effect, because some compounds from this group have been found to be protective in HD models. The beneficial potency of valproate was further supported by the findings that it exerted neuroprotection in tg mouse models of amyotrophic lateral sclerosis (applied doses: 150-250400 mg/kg ip; Rouaux et al., 2007) and Alzheimer's disease (applied dose: 30 mg/kg ip; Qing et al., 2008). Furthermore, it has also been demonstrated to be protective in the malonate model of HD in rats (applied dose: $300 \mathrm{mg} / \mathrm{kg}$ ip; Morland et al., 2004). As we observed dose-dependent acute toxicity in higher doses in mice (significant above $500 \mathrm{mg} / \mathrm{kg}$ ip) and also aggravation of 1-methyl-4-phenyl-1,2,3,6-tetrahydropyridine (MPTP) toxicity following 
administration in a subacute dosing regime in mice (significant at $250 \mathrm{mg} / \mathrm{kg}$ ip), the dose of $100 \mathrm{mg} / \mathrm{kg}$ was chosen for chronic administration purposes in our experiments.

The available scientific data as regards the altered tryptophan metabolism in HD indicate that an enhancement of the KYNA effect may exert neuroprotection. However, from pharmacological considerations, KYNA itself has several disadvantages, which rule out its systemic use in the treatment of HD. Accordingly, several new KYNA analogues or prodrugs have been designed (reviewed by Schwarcz, 2004). An important group of these compounds are the KYNA amides (including our novel agent), which are excellent candidates (reviewed by Fulop et al., 2009), because these analogues are known to be capable of the selective inhibition of the NR2B subunit containing NMDA receptors too (Borza et al., 2007). This analogue has already been proved to be beneficial in rat migraine models (applied dose: 300 $\mathrm{mg} / \mathrm{kg}$ ip; Vamos et al., 2009a; Vamos et al., 2010). As acute administration of the novel KYNA analogue in a dose of $300 \mathrm{mg} / \mathrm{kg}$ caused slight discomfort of the rats and this shortlasting effect was also detected in mice, we selected a dose of $100 \mathrm{mg} / \mathrm{kg}$ for chronic administration.

Using the N171-82Q tg mouse model of HD, we tested the effects of valproate and the novel KYNA amide on survival. Valproate and the KYNA amide increased the survival time of the N171-82Q tg mice significantly (by $31.4 \%$ and $30.7 \%$, respectively). These elevations are noteworthy: the most effective agent in this model, probenecid, lengthened the survival by $\sim 35 \%$ (Vamos et al., 2009b), while tiagabine did so by 26\% (Masuda et al., 2008) and phenylbutyrate by $23 \%$ (Gardian et al., 2005). Nevertheless, it is important to distinguish between the characteristic of the survival curves. Valproate seems to shift the survival curve of the N171-82Q tg animals, i.e. it delays the onset of mortality (as in the case of phenylbutyrate treatment). The treatment with the KYNA analogue did not simply shift the survival curve of the N171-82Q tg animals, but also altered the slope of the curve, i.e. the longer the treatment period, the more pronounced the prolongation of survival duration was. Hence, this compound seems to slow down the progress of neurodegeneration instead of only delaying the onset of mortality.

The beneficial effect of valproate and the KYNA amide is supported by our findings in the open-field tests, too. As regards the spontaneous locomotor activity, valproate exerted a significant protective effect at 10-12 weeks of age (weeks 4-6 of treatment), measured by 
means of ambulation distance and local time. The local time data for the third period of treatment also clearly demonstrate the significant amelioration. It is worth noting here that there was no detectable side-effect of the treatment in the wt mice as regards the spontaneous locomotor activity, although the treatment caused significant increases in ambulation distance in the N171-82Q tg animals as compared with the untreated wt mice. Thus, as we did not observe a similar difference between the treated and the untreated wt mice, the considerable increase in locomotion mentioned above is probably due to the combined effect resulting from the treatment and the presence of the transgene. Accordingly, the phenomenon can be explained in that there are regional differences in the effects of valproate on the GABA levels in certain brain areas. For example, there is a considerable elevation in midbrain regions such as the substantia nigra (Iadarola et al., 1979; Loscher et al., 1985), the reticular part of which is an important part of both direct and indirect pathways of the basal ganglia circuitry. In HD, the function of the indirect pathway deteriorates first, while the direct pathway remains intact in the early stages (reviewed by Ramaswamy et al., 2007), resulting in hyperkinetic movements in humans. The treatment probably shifts the function of the direct pathway by elevating the GABA level in the substantia nigra pars reticulata with decreased inhibition of the thalamus, resulting in increased locomotion. It is also worth mentioning that chronic valproate treatment did not influence the striatal levels of DA and its metabolites, which would also have influenced the motor performance. Furthermore, as valproate has anxiolytic effects only in higher doses (200-300-400 mg/kg ip; de Angelis, 1995) and there is no documented stereotypy-inducing effect in the scientific literature, it is unlikely that the treatment had any effect on these parameters, thereby influencing the spontaneous locomotor activity. In addition to the beneficial effects on spontaneous locomotor activity, valproate exerted a significant amelioration in the exploratory activity, measured by means of the number of rearings, while it did not have significant effects in wt mice. Although the treatment with the KYNA analogue also ameliorated the hypolocomotion of the N171-82Q $\operatorname{tg}$ mice, the locomotor activity of the N171-82Q tg mice had improved to the wt level only by the end of the 9-week treatment period, as measured by means of ambulation distance and immobility time. As the KYNA analogue did not influence the locomotor activity and not induce anxiolysis or stereotypy at the dose administered in the wt mice, the beneficial change in hypolocomotion is not due to any behavioural side-effect of the KYNA amide treatment. 
The late-onset amelioration is probably explained by the observation that N171-82Q mice adapt to NMDA receptor-induced excitotoxicity in an increasing manner during aging (Jarabek et al., 2004). The antiexcitotoxic therapy probably supports the adaptive processes, leading to a significantly enhanced level of protection. The treatment with the KYNA analogue did not influence the exploratory activity either in N171-82Q tg or in wt mice. Although there is a seeming variation between the different sets of N171-82Q strain generations as regards the extent of alteration in local time (the duration of the lack of locomotion) or immobility time (the duration of immobility), both of these parameters are applicable for the measurement of hypolocomotion, and the alterations are usually consistent with those in the ambulation distance data. Nevertheless, for the study of drug effects on hypolocomotion, the selection of that parameter is more advisable as it reveals a larger difference between the N171-82Q tg and wt animals even at the beginning of the experiment.

As neuroprotective properties of valproate are well supported by the histology data from the scientific literature, only preliminary qualitative examinations were carried out on brain pathology by means of cresyl violet staining and anti-huntingtin immunohistochemistry. The findings indicated that the cellular atrophy was present in treated animals, but its extent was lower than that in untreated N171-82Q tg mice (data not shown). These findings are consistent with the data from studies with other HDAC inhibitors, but valproate does not seem to exert such pronounced effects as those substances. In contrast with the previous studies with HDAC inhibitor molecules, where the huntingtin aggregate deposition was not altered, our provisory data suggest that valproate treatment diminished the striatal antihuntingtin immunoreactivity (examined with EM48 antibody). This phenomenon might be explained in that the pharmacological activity of valproate is more complex than that its effects can be interpreted solely through its HDAC inhibitor activity.

As neuroprotective properties of the novel KYNA analogue had never been verified before, thorough examinations on anatomical changes were carried out. The body weight data well support the findings of survival and behavioural analyses, for the treatment significantly mitigated the characteristic phenomenon that the body weight of N171-82Q tg mice does not increase further after 2 months of age. Furthermore, our brain pathology data are in accordance with the findings of Schilling et al., 1999 (the first characterization of N171-82Q $\operatorname{tg}$ mice), who reported that the brains of tg animals are slightly smaller (by $7.9 \%$ in our 
experiment). However, precise unbiased design-based stereological procedures were necessary to investigate the number of neurons and their size in the striatum, in order to reveal the possible pathomechanism of HD at the cellular level in these N171-82Q tg animals. In parallel with the difference in brain weights, the volume of the striatum was lower (by $12.6 \%$ ) in the N171-82Q tg animals. This phenomenon can be well explained by the $14 \%$ lower $\mathrm{V}_{\mathrm{N}}$. This suggests that neuronal atrophy plays a more important role in the pathomechanism in the N171-82Q tg mouse model of HD than the possible final decrease in the number of neurons. This observation is in accordance with the original characterization of these N171-82Q tg mice, which did not indicate a severe loss of neurons in the striatum. Indeed, it has been demonstrated that some drugs have beneficial effects on neuronal atrophy (e.g. Gardian et al., 2005; Stack et al., 2010), and it therefore seems to be a good parameter via which to test neuroprotective effects of drugs. In our experiments with the novel KYNA amide, the neuronal atrophy was nearly completely mitigated. As concerns the aggregation pathology, we investigated the percentage of $\mathrm{EM} 48^{+}$nuclei in the striatum. This revealed that the treatment led to a slight, but not significant improvement.

The KYNA precursor L-KYN might also be of therapeutic potential, as it has already been found to be protective in rat, mouse and gerbil models of cerebral ischaemia (applied dose: 300 mg/kg ip; Nozaki and Beal, 1992; applied doses: 100-300 mg/kg ip; Gigler et al., 2007). The dose of L-KYN was also selected to be $100 \mathrm{mg} / \mathrm{kg}$ to permit approximately equimolar testing with the KYNA analogue. The lack of significant effects on survival in the case of L-KYN could be due to several reasons. Although L-KYN has been found to be protective alone in brain ischaemia models or in combination therapy with probenecid in a migraine (Knyihar-Csillik et al., 2007) or ischaemia model (Robotka et al., 2008), these beneficial effects were seen after an acute event with sudden onset. The transformation of L$\mathrm{KYN}$ in these acute conditions is probably mediated mainly towards KYNA production. However, in the N171-82Q HD model with prolonged disease onset and a likely disturbance of the tryptophan metabolism, L-KYN probably transforms towards the toxic metabolites, too, following its chronic administration. Thus, although L-KYN administration seems beneficial in acute conditions, it is probably invaluable in the treatment of conditions with prolonged onset. 
The protective effects of L-carnosine with antioxidant, antiglycator and metal chelator properties have been proved against permanent cerebral ischaemia in mice (applied doses: $500-1000 \mathrm{mg} / \mathrm{kg} \mathrm{ip}$; Rajanikant et al., 2007) and against ischaemic-reperfusion injury in rats and gerbils (applied dose: $100 \mathrm{mg} / \mathrm{kg}$ ip; Dobrota et al., 2005), and the dose of $200 \mathrm{mg} / \mathrm{kg}$ was therefore selected as chronic dosing regime. L-Carnosine exerted a slight, but not significant amelioration of survival. Although in higher doses it has been found to be protective against permanent cerebral ischaemia in mice, the possible amelioration achieved by extremely high doses would have only scientific, but not therapeutic significance. Above $100-200 \mathrm{mg} / \mathrm{kg}$ (taking into consideration the higher metabolic rate of rodents, too), the possibility of costeffective production and of finding an appropriate route of daily administration for human use is questionable.

The PPAR- $\gamma$ agonist pioglitazone has already been found to be beneficial in an MPTP model of Parkinson's disease (applied dose: approximately $20 \mathrm{mg} / \mathrm{kg}$ per os; Breidert et al., 2002), in a tg mouse model of amyotrophic lateral sclerosis (applied dose: 1200 ppm per os; Kiaei et al., 2005) and after a global cerebral ischaemic-reperfusion injury in gerbils (applied dose: 3-10-30 mg/kg in dimethyl sulfoxide (DMSO) ip; Kaundal et al., 2009). On the one hand, oral dosing regimes are unreliable and they make it difficult to carry out experiments in a cost-effective way; on the other hand, the chronic use of DMSO for vehicle purposes should be avoided for toxicity reasons. We therefore decided on a dose of $5 \mathrm{mg} / \mathrm{kg}$ and the ip mode of administration of pioglitazone in suspension using $0.1 \%$ (wt/vol) carboxymethylcellulose solution. Pioglitazone at a dose of $5 \mathrm{mg} / \mathrm{kg}$ was clearly ineffective. Indeed, it slightly decreased the mean survival time of the N171-82Q tg animals. This phenomenon could be due to the fact that the chronic ip administration of suspended particles has slight local toxic effects which, although they do not exert any seeming deterioration in wt animals, can probably cause disease worsening in mice predestinated to chronic progressive disease development. Furthermore, higher doses have been applied in most of the previous experiments, so subdosing would be another reason for the lack of efficacy. This possibility is supported by the very recent finding that pioglitazone $(10-20-40 \mathrm{mg} / \mathrm{kg}$ per os for 21 days) in suspension in $0.25 \%$ (wt/vol) carboxymethylcellulose solution has been found protective in the QUIN model of HD in rats (Kalonia et al., 2010). 
BZS1514 was previously found to be protective in a tg mouse model of Alzheimer's disease (applied dose: $10 \mathrm{mg} / \mathrm{kg}$ ip; personal communication, data not shown). However, as the targets of this molecule in HD would include intranuclear alterations, too, a higher dose of $20 \mathrm{mg} / \mathrm{kg}$ was selected. BZS1514 exerted only a slight, but not significant amelioration of survival at the twofold dose. The lack of clear efficacy may be explained in that the achievement of significant intracellular/intranuclear effects needs even higher doses.

\section{Conclusions}

The beneficial effects of valproate in survival and behavioural analyses are probably due to its complex activity, i.e. the increases in GABAergic function, and anti-excitotoxic and HDAC inhibitor effects. In the 1970s, several clinical trials were carried out with valproate in HD, usually with the aim of amelioration of the choreiform movements, but without any positive effect (Bachman et al., 1977; Pearce et al., 1977; Symington et al., 1978). However, in the present decade, two studies have revealed that valproate is beneficial in monotherapy in the treatment of myoclonus in HD (Saft et al., 2006) and in combination therapy with olanzapine in the treatment of psychosis and movement disorders related to HD (Grove et al., 2000). Nevertheless, we should be cautious with the interpretation of our preclinical results, especially when the findings of previously failed clinical trials are considered. The treatment with valproate merely delayed the onset of the symptoms, and did not alter the characteristics of the survival curve; its effect therefore seems to be mainly symptomatic, which is supported by the preliminary findings on brain pathology. Furthermore, we began our experiments before the onset of motor symptoms, whereas the earlier studies were carried out on patients with manifest clinical symptoms of HD. Nevertheless, it is worth considering the design of further preclinical studies with valproate and, in the event of reinforcing results, the setting up of new clinical trials based on a well-planned treatment regime, using valproate in monotherapy or in combination therapy with a high number of participating patients. The novel KYNA analogue, which can probably exert complex anti-excitotoxic effects, also ameliorated the characteristic phenomena caused by the presence of transgene. However, in contrast with the findings in the survival analysis in the experiment with valproate, it altered the characteristic of the survival curve, suggesting neuroprotective effects. The neuroprotection was verified by thorough stereological analyses, and this novel compound 
may therefore be considered a promising candidate for further preclinical and clinical trials. It is also noteworthy as regards future experiments that we did not detect any side-effect either of valproate or of the novel KYNA analogue at the applied dose. Although L-KYN, Lcarnosine, pioglitazone and BZS1514 did not exert any significant amelioration in the survival analyses of our experiments, new dosing and administration regimes or the application of combination therapies may lead to the achievement of beneficial effects, if they have any.

\section{Acknowledgements}

I would like to express my gratitude to my supervisor Dr. Péter Klivényi, Associate Professor at the Department of Neurology, University of Szeged, and to Prof. Dr. László Vécsei, Member of the Hungarian Academy of Sciences, Head of the Department of Neurology, University of Szeged, for their excellent scientific guidance and continuous support of my research activities.

I would also like to thank all colleagues with whom I performed the experiments, especially Dr. Gábor Nyiri, Senior Research Fellow at the Institute of Experimental Medicine, Hungarian Academy of Sciences, Budapest, Dr. Enikő Vámos and Imola Plangár, former and present $\mathrm{PhD}$ students at the Department of Neurology, University of Szeged, and Andrea Geisz and Tünde Tőkés, who carried out scientific research activities as students under my practical supervision at the Department of Neurology, University of Szeged. I would like to acknowledge the technical help of Andrea Varga, Ágnes Koszó and Valéria Széll Vékonyné, and the valuable scientific advice of Dr. Tamás Zsigmond Kincses, Assistant Lecturer at the Department of Neurology, University of Szeged. Furthermore, I would like to express my special thanks to Prof. Dr. Ferenc Fülöp, Member of the Hungarian Academy of Sciences, Head of the Department of Pharmaceutical Chemistry, University of Szeged, for the kind gift of $\mathrm{N}$-(2- $N, N$-dimethylaminoethyl)-4-oxo-1H-quinoline-2-carboxamide hydrochloride, and to Prof. Dr. Botond Penke, Member of the Hungarian Academy of Sciences, previous Head of the Department of Medicinal Chemistry, University of Szeged, for the kind gift of BZS1514 for our research purposes. Additionally, I would like to say special thanks to Prof. Dr. Tamás F. Freund, Member of the Hungarian Academy of Sciences, Director of the Institute of Experimental Medicine, Hungarian Academy of Sciences, Budapest, for the possibility to 
become familiar with fine immunohistochemistry methods and stereology in the Cellular and Network Neurobiology Department, and to Dr. László G. Hársing Jr., previous Head of Division of Preclinical Research at EGIS Pharmaceuticals Plc, for the possibility to become familiar with the techniques of electrochemical detection.

I would like to express my special gratitude to my family for their continuous support throughout my work. I wish to dedicate all of my scientific work to the memory of my father, Dénes Zádori Sr., who passed away in October, 2010 after battling a prolonged and devastating neurodegenerative illness.

\section{References}

Adam OR, Jankovic J (2008) Symptomatic treatment of Huntington disease. Neurotherapeutics 5: 181-97

Bachman DS, Butler IJ, McKhann GM (1977) Long-term treatment of juvenile Huntington's chorea with dipropylacetic acid. Neurology 27: 193-7

Bahn A, Ljubojevic M, Lorenz H, Schultz C, Ghebremedhin E, Ugele B, Sabolic I, Burckhardt G, Hagos Y (2005) Murine renal organic anion transporters mOAT1 and mOAT3 facilitate the transport of neuroactive tryptophan metabolites. Am J Physiol Cell Physiol 289: C1075-84

Beal MF, Brouillet E, Jenkins B, Henshaw R, Rosen B, Hyman BT (1993a) Age-dependent striatal excitotoxic lesions produced by the endogenous mitochondrial inhibitor malonate. J Neurochem 61: 1147-50

Beal MF, Brouillet E, Jenkins BG, Ferrante RJ, Kowall NW, Miller JM, Storey E, Srivastava R, Rosen BR, Hyman BT (1993b) Neurochemical and histologic characterization of striatal excitotoxic lesions produced by the mitochondrial toxin 3-nitropropionic acid. J Neurosci 13: 4181-92

Beal MF, Kowall NW, Ellison DW, Mazurek MF, Swartz KJ, Martin JB (1986) Replication of the neurochemical characteristics of Huntington's disease by quinolinic acid. Nature 321: $168-71$ 
Beal MF, Matson WR, Swartz KJ, Gamache PH, Bird ED (1990) Kynurenine pathway measurements in Huntington's disease striatum: evidence for reduced formation of kynurenic acid. J Neurochem 55: 1327-39

Birch PJ, Grossman CJ, Hayes AG (1988) Kynurenate and FG9041 have both competitive and non-competitive antagonist actions at excitatory amino acid receptors. Eur $\mathrm{J}$ Pharmacol 151: 313-5

Boldyrev AA, Stvolinsky SL, Fedorova TN, Suslina ZA (2010) Carnosine as a natural antioxidant and geroprotector: from molecular mechanisms to clinical trials. Rejuvenation Res 13: 156-8

Bordelon YM, Chesselet MF (1999) Early effects of intrastriatal injections of quinolinic acid on microtubule-associated protein-2 and neuropeptides in rat basal ganglia. Neuroscience 93: 843-53

Borrell-Pages M, Zala D, Humbert S, Saudou F (2006) Huntington's disease: from huntingtin function and dysfunction to therapeutic strategies. Cell Mol Life Sci 63: 2642-60

Borza I, Kolok S, Galgoczy K, Gere A, Horvath C, Farkas S, Greiner I, Domany G (2007) Kynurenic acid amides as novel NR2B selective NMDA receptor antagonists. Bioorg Med Chem Lett 17: 406-9

Breidert T, Callebert J, Heneka MT, Landreth G, Launay JM, Hirsch EC (2002) Protective action of the peroxisome proliferator-activated receptor-gamma agonist pioglitazone in a mouse model of Parkinson's disease. J Neurochem 82: 615-24

Centonze D, Bernardi G, Koch G (2007) Mechanisms of disease: basic-research-driven investigations in humans--the case of hyperkinetic disorders. Nat Clin Pract Neurol 3: $572-80$

Cha JH (2000) Transcriptional dysregulation in Huntington's disease. Trends Neurosci 23: $387-92$

Chen N, Luo T, Wellington C, Metzler M, McCutcheon K, Hayden MR, Raymond LA (1999) Subtype-specific enhancement of NMDA receptor currents by mutant huntingtin. J Neurochem 72: 1890-8

Connick JH, Stone TW (1988) Quinolinic acid effects on amino acid release from the rat cerebral cortex in vitro and in vivo. Br J Pharmacol 93: 868-76 
Coyle JT, Schwarcz R (1976) Lesion of striatal neurones with kainic acid provides a model for Huntington's chorea. Nature 263: 244-6

Cui L, Jeong H, Borovecki F, Parkhurst CN, Tanese N, Krainc D (2006) Transcriptional repression of PGC-1alpha by mutant huntingtin leads to mitochondrial dysfunction and neurodegeneration. Cell 127: 59-69

Csillik A, Knyihar E, Okuno E, Krisztin-Peva B, Csillik B, Vecsei L (2002) Effect of 3nitropropionic acid on kynurenine aminotransferase in the rat brain. Exp Neurol 177: 233-41

de Almeida LP, Ross CA, Zala D, Aebischer P, Deglon N (2002) Lentiviral-mediated delivery of mutant huntingtin in the striatum of rats induces a selective neuropathology modulated by polyglutamine repeat size, huntingtin expression levels, and protein length. J Neurosci 22: 3473-83

de Angelis L (1995) Effects of valproate and lorazepam on experimental anxiety: tolerance, withdrawal, and role of clonidine. Pharmacol Biochem Behav 52: 329-33

de Carvalho LP, Bochet P, Rossier J (1996) The endogenous agonist quinolinic acid and the non endogenous homoquinolinic acid discriminate between NMDAR2 receptor subunits. Neurochem Int 28: 445-52

DiFiglia M (1990) Excitotoxic injury of the neostriatum: a model for Huntington's disease. Trends Neurosci 13: 286-9

DiFiglia M, Sapp E, Chase KO, Davies SW, Bates GP, Vonsattel JP, Aronin N (1997) Aggregation of huntingtin in neuronal intranuclear inclusions and dystrophic neurites in brain. Science 277: 1990-3

Dobrota D, Fedorova T, Stvolinsky S, Babusikova E, Likavcanova K, Drgova A, Strapkova A, Boldyrev A (2005) Carnosine protects the brain of rats and Mongolian gerbils against ischemic injury: after-stroke-effect. Neurochem Res 30: 1283-8

Evers-Kiebooms G, Nys K, Harper P, Zoeteweij M, Durr A, Jacopini G, Yapijakis C, Simpson S (2002) Predictive DNA-testing for Huntington's disease and reproductive decision making: a European collaborative study. Eur J Hum Genet 10: 167-76

Ferrante RJ, Kubilus JK, Lee J, Ryu H, Beesen A, Zucker B, Smith K, Kowall NW, Ratan RR, Luthi-Carter R, Hersch SM (2003) Histone deacetylase inhibition by sodium 
butyrate chemotherapy ameliorates the neurodegenerative phenotype in Huntington's disease mice. J Neurosci 23: 9418-27

Folstein SE, Chase GA, Wahl WE, McDonnell AM, Folstein MF (1987) Huntington disease in Maryland: clinical aspects of racial variation. Am J Hum Genet 41: 168-79

Fonnum F, Storm-Mathisen J, Divac I (1981) Biochemical evidence for glutamate as neurotransmitter in corticostriatal and corticothalamic fibres in rat brain. Neuroscience 6: $863-73$

Fukui S, Schwarcz R, Rapoport SI, Takada Y, Smith QR (1991) Blood-brain barrier transport of kynurenines: implications for brain synthesis and metabolism. J Neurochem 56: 2007-17

Fulop F, Szatmari I, Vamos E, Zadori D, Toldi J, Vecsei L (2009) Syntheses, transformations and pharmaceutical applications of kynurenic acid derivatives. Curr Med Chem 16: 4828-42

Gafni J, Ellerby LM (2002) Calpain activation in Huntington's disease. J Neurosci 22: 4842-9

Gardian G, Browne SE, Choi DK, Klivenyi P, Gregorio J, Kubilus JK, Ryu H, Langley B, Ratan RR, Ferrante RJ, Beal MF (2005) Neuroprotective effects of phenylbutyrate in the N171-82Q transgenic mouse model of Huntington's disease. J Biol Chem 280: $556-63$

Gardian G, Vecsei L (2004) Huntington's disease: pathomechanism and therapeutic perspectives. J Neural Transm 111: 1485-94

Gigler G, Szenasi G, Simo A, Levay G, Harsing LG, Jr., Sas K, Vecsei L, Toldi J (2007) Neuroprotective effect of L-kynurenine sulfate administered before focal cerebral ischemia in mice and global cerebral ischemia in gerbils. Eur J Pharmacol 564: 116-22

Gould DH, Gustine DL (1982) Basal ganglia degeneration, myelin alterations, and enzyme inhibition induced in mice by the plant toxin 3-nitropropanoic acid. Neuropathol Appl Neurobiol 8: 377-93

Gram L, Larsson OM, Johnsen AH, Schousboe A (1988) Effects of valproate, vigabatrin and aminooxyacetic acid on release of endogenous and exogenous GABA from cultured neurons. Epilepsy Res 2: 87-95

Grove VE, Jr., Quintanilla J, DeVaney GT (2000) Improvement of Huntington's disease with olanzapine and valproate. N Engl J Med 343: 973-4 
Guidetti P, Bates GP, Graham RK, Hayden MR, Leavitt BR, MacDonald ME, Slow EJ, Wheeler VC, Woodman B, Schwarcz R (2006) Elevated brain 3-hydroxykynurenine and quinolinate levels in Huntington disease mice. Neurobiol Dis 23: 190-7

Guidetti P, Luthi-Carter RE, Augood SJ, Schwarcz R (2004) Neostriatal and cortical quinolinate levels are increased in early grade Huntington's disease. Neurobiol Dis 17: $455-61$

Gutekunst CA, Li SH, Yi H, Mulroy JS, Kuemmerle S, Jones R, Rye D, Ferrante RJ, Hersch SM, Li XJ (1999) Nuclear and neuropil aggregates in Huntington's disease: relationship to neuropathology. J Neurosci 19: 2522-34

Hardingham GE, Fukunaga Y, Bading H (2002) Extrasynaptic NMDARs oppose synaptic NMDARs by triggering CREB shut-off and cell death pathways. Nat Neurosci 5: 40514

Harris CA, Miranda AF, Tanguay JJ, Boegman RJ, Beninger RJ, Jhamandas K (1998) Modulation of striatal quinolinate neurotoxicity by elevation of endogenous brain kynurenic acid. Br J Pharmacol 124: 391-9

Hashimoto R, Hough C, Nakazawa T, Yamamoto T, Chuang DM (2002) Lithium protection against glutamate excitotoxicity in rat cerebral cortical neurons: involvement of NMDA receptor inhibition possibly by decreasing NR2B tyrosine phosphorylation. J Neurochem 80: 589-97

Heng MY, Detloff PJ, Wang PL, Tsien JZ, Albin RL (2009) In vivo evidence for NMDA receptor-mediated excitotoxicity in a murine genetic model of Huntington disease. $\mathrm{J}$ Neurosci 29: 3200-5

Hersch SM, Ferrante RJ (2004) Translating therapies for Huntington's disease from genetic animal models to clinical trials. NeuroRx 1:298-306

Hetenyi C, van der Spoel D (2002) Efficient docking of peptides to proteins without prior knowledge of the binding site. Protein Science 11: 1729-37

Higgins LS, Depaoli AM (2010) Selective peroxisome proliferator-activated receptor gamma (PPARgamma) modulation as a strategy for safer therapeutic PPARgamma activation. Am J Clin Nutr 91: 267S-72S

Hilmas C, Pereira EF, Alkondon M, Rassoulpour A, Schwarcz R, Albuquerque EX (2001) The brain metabolite kynurenic acid inhibits alpha7 nicotinic receptor activity and 
increases non-alpha7 nicotinic receptor expression: physiopathological implications. J Neurosci 21: 7463-73

Hockly E, Richon VM, Woodman B, Smith DL, Zhou X, Rosa E, Sathasivam K, Ghazi-Noori S, Mahal A, Lowden PA, Steffan JS, Marsh JL, Thompson LM, Lewis CM, Marks PA, Bates GP (2003) Suberoylanilide hydroxamic acid, a histone deacetylase inhibitor, ameliorates motor deficits in a mouse model of Huntington's disease. Proc Natl Acad Sci U S A 100: 2041-6

Hodgson JG, Agopyan N, Gutekunst CA, Leavitt BR, LePiane F, Singaraja R, Smith DJ, Bissada N, McCutcheon K, Nasir J, Jamot L, Li XJ, Stevens ME, Rosemond E, Roder JC, Phillips AG, Rubin EM, Hersch SM, Hayden MR (1999) A YAC mouse model for Huntington's disease with full-length mutant huntingtin, cytoplasmic toxicity, and selective striatal neurodegeneration. Neuron 23: 181-92

Hoffner G, Soues S, Djian P (2007) Aggregation of expanded huntingtin in the brains of patients with Huntington disease. Prion 1: 26-31

Huey R, Morris GM, Olson AJ, Goodsell DS (2007) A semiempirical free energy force field with charge-based desolvation. J Comp Chem 28: 1145-52

Hunt MJ, Morton AJ (2005) Atypical diabetes associated with inclusion formation in the R6/2 mouse model of Huntington's disease is not improved by treatment with hypoglycaemic agents. Exp Brain Res 166: 220-9

Iadarola MJ, Raines A, Gale K (1979) Differential effects of n-dipropylacetate and aminooxyacetic acid on gamma-aminobutyric acid levels in discrete areas of rat brain. $\mathrm{J}$ Neurochem 33: 1119-23

Igarashi S, Morita H, Bennett KM, Tanaka Y, Engelender S, Peters MF, Cooper JK, Wood JD, Sawa A, Ross CA (2003) Inducible PC12 cell model of Huntington's disease shows toxicity and decreased histone acetylation. Neuroreport 14: 565-8

Jarabek BR, Yasuda RP, Wolfe BB (2004) Regulation of proteins affecting NMDA receptorinduced excitotoxicity in a Huntington's mouse model. Brain 127: 505-16

Jauch D, Urbanska EM, Guidetti P, Bird ED, Vonsattel JP, Whetsell WO, Jr., Schwarcz R (1995) Dysfunction of brain kynurenic acid metabolism in Huntington's disease: focus on kynurenine aminotransferases. J Neurol Sci 130: 39-47 
Johannessen CU, Johannessen SI (2003) Valproate: past, present, and future. CNS Drug Rev 9: $199-216$

Kalonia H, Kumar P, Kumar A (2010) Pioglitazone ameliorates behavioral, biochemical and cellular alterations in quinolinic acid induced neurotoxicity: possible role of peroxisome proliferator activated receptor-Upsilon (PPARUpsilon) in Huntington's disease. Pharmacol Biochem Behav 96: 115-24

Kaundal RK, Iyer S, Kumar A, Sharma SS (2009) Protective effects of pioglitazone against global cerebral ischemic-reperfusion injury in gerbils. J Pharmacol Sci 109: 361-7

Kazantsev AG, Hersch SM (2007) Drug targeting of dysregulated transcription in Huntington's disease. Prog Neurobiol 83: 249-59

Kessler M, Terramani T, Lynch G, Baudry M (1989) A glycine site associated with Nmethyl-D-aspartic acid receptors: characterization and identification of a new class of antagonists. J Neurochem 52: 1319-28

Kiaei M (2008) Peroxisome Proliferator-Activated Receptor-gamma in Amyotrophic Lateral Sclerosis and Huntington's Disease. PPAR Res 2008: 418765

Kiaei M, Kipiani K, Chen J, Calingasan NY, Beal MF (2005) Peroxisome proliferatoractivated receptor-gamma agonist extends survival in transgenic mouse model of amyotrophic lateral sclerosis. Exp Neurol 191: 331-6

Kim YJ, Yi Y, Sapp E, Wang Y, Cuiffo B, Kegel KB, Qin ZH, Aronin N, DiFiglia M (2001) Caspase 3-cleaved N-terminal fragments of wild-type and mutant huntingtin are present in normal and Huntington's disease brains, associate with membranes, and undergo calpain-dependent proteolysis. Proc Natl Acad Sci U S A 98: 12784-9

Klivenyi P, Bende Z, Hartai Z, Penke Z, Nemeth H, Toldi J, Vecsei L (2006) Behaviour changes in a transgenic model of Huntington's disease. Behav Brain Res 169: 137-41

Knyihar-Csillik E, Toldi J, Mihaly A, Krisztin-Peva B, Chadaide Z, Nemeth H, Fenyo R, Vecsei L (2007) Kynurenine in combination with probenecid mitigates the stimulation-induced increase of c-fos immunoreactivity of the rat caudal trigeminal nucleus in an experimental migraine model. J Neural Transm 114: 417-21

Kostrouchova M, Kostrouch Z, Kostrouchova M (2007) Valproic acid, a molecular lead to multiple regulatory pathways. Folia Biol (Praha) 53: 37-49 
Kramer OH, Zhu P, Ostendorff HP, Golebiewski M, Tiefenbach J, Peters MA, Brill B, Groner B, Bach I, Heinzel T, Gottlicher M (2003) The histone deacetylase inhibitor valproic acid selectively induces proteasomal degradation of HDAC2. EMBO J 22: 3411-20

Kuppenbender KD, Standaert DG, Feuerstein TJ, Penney JB, Jr., Young AB, Landwehrmeyer GB (2000) Expression of NMDA receptor subunit mRNAs in neurochemically identified projection and interneurons in the human striatum. J Comp Neurol 419: 40721

Landwehrmeyer GB, Standaert DG, Testa CM, Penney JB, Jr., Young AB (1995) NMDA receptor subunit mRNA expression by projection neurons and interneurons in rat striatum. J Neurosci 15: 5297-307

Langley B, Gensert JM, Beal MF, Ratan RR (2005) Remodeling chromatin and stress resistance in the central nervous system: histone deacetylase inhibitors as novel and broadly effective neuroprotective agents. Curr Drug Targets CNS Neurol Disord 4: 4150

Lin CH, Tallaksen-Greene S, Chien WM, Cearley JA, Jackson WS, Crouse AB, Ren S, Li XJ, Albin RL, Detloff PJ (2001) Neurological abnormalities in a knock-in mouse model of Huntington's disease. Hum Mol Genet 10: 137-44

Liu Y, Wong TP, Aarts M, Rooyakkers A, Liu L, Lai TW, Wu DC, Lu J, Tymianski M, Craig AM, Wang YT (2007) NMDA receptor subunits have differential roles in mediating excitotoxic neuronal death both in vitro and in vivo. J Neurosci 27: 2846-57

Loscher W (1981a) Effect of inhibitors of GABA aminotransferase on the metabolism of GABA in brain tissue and synaptosomal fractions. J Neurochem 36: 1521-7

Loscher W (1981b) Valproate induced changes in GABA metabolism at the subcellular level. Biochem Pharmacol 30: 1364-6

Loscher W (1999) Valproate: a reappraisal of its pharmacodynamic properties and mechanisms of action. Prog Neurobiol 58: 31-59

Loscher W, Vetter M, Bohme G, Stoltenburg-Didinger G (1985) In vivo effects of anticonvulsant drugs on nerve terminal (synaptosomal) GABA levels in 11 brain regions of the rat. J Neural Transm 63: 157-67

Mangiarini L, Sathasivam K, Seller M, Cozens B, Harper A, Hetherington C, Lawton M, Trottier Y, Lehrach H, Davies SW, Bates GP (1996) Exon 1 of the HD gene with an 
expanded CAG repeat is sufficient to cause a progressive neurological phenotype in transgenic mice. Cell 87: 493-506

Marchi M, Risso F, Viola C, Cavazzani P, Raiteri M (2002) Direct evidence that releasestimulating alpha7* nicotinic cholinergic receptors are localized on human and rat brain glutamatergic axon terminals. J Neurochem 80: 1071-8

Masuda N, Peng Q, Li Q, Jiang M, Liang Y, Wang X, Zhao M, Wang W, Ross CA, Duan W (2008) Tiagabine is neuroprotective in the N171-82Q and R6/2 mouse models of Huntington's disease. Neurobiol Dis 30: 293-302

McGeer EG, McGeer PL (1976) Duplication of biochemical changes of Huntington's chorea by intrastriatal injections of glutamic and kainic acids. Nature 263: 517-9

McNamara FN, Clifford JJ, Tighe O, Kinsella A, Drago J, Croke DT, Waddington JL (2003) Congenic D1A dopamine receptor mutants: ethologically based resolution of behavioural topography indicates genetic background as a determinant of knockout phenotype. Neuropsychopharmacology 28: 86-99

Menalled LB, Sison JD, Dragatsis I, Zeitlin S, Chesselet MF (2003) Time course of early motor and neuropathological anomalies in a knock-in mouse model of Huntington's disease with 140 CAG repeats. J Comp Neurol 465: 11-26

Milnerwood AJ, Gladding CM, Pouladi MA, Kaufman AM, Hines RM, Boyd JD, Ko RW, Vasuta OC, Graham RK, Hayden MR, Murphy TH, Raymond LA (2010) Early increase in extrasynaptic NMDA receptor signaling and expression contributes to phenotype onset in Huntington's disease mice. Neuron 65: 178-90

Morland C, Boldingh KA, Iversen EG, Hassel B (2004) Valproate is neuroprotective against malonate toxicity in rat striatum: an association with augmentation of high-affinity glutamate uptake. J Cereb Blood Flow Metab 24: 1226-34

Morris GM, Goodsell DS, Halliday RS, Huey R, Hart WE, Belew RK, Olson AJ (1998) Automated docking using a Lamarckian genetic algorithm and an empirical binding free energy function. J Comp Chem 19: 1639-62

Nagai Y, Inui T, Popiel HA, Fujikake N, Hasegawa K, Urade Y, Goto Y, Naiki H, Toda T (2007) A toxic monomeric conformer of the polyglutamine protein. Nat Struct Mol Biol 14: 332-40 
Nozaki K, Beal MF (1992) Neuroprotective effects of L-kynurenine on hypoxia-ischemia and NMDA lesions in neonatal rats. J Cereb Blood Flow Metab 12: 400-7

Okamoto S, Pouladi MA, Talantova M, Yao D, Xia P, Ehrnhoefer DE, Zaidi R, Clemente A, Kaul M, Graham RK, Zhang D, Vincent Chen HS, Tong G, Hayden MR, Lipton SA (2009) Balance between synaptic versus extrasynaptic NMDA receptor activity influences inclusions and neurotoxicity of mutant huntingtin. Nat Med 15: 1407-13

Orr AL, Li S, Wang CE, Li H, Wang J, Rong J, Xu X, Mastroberardino PG, Greenamyre JT, Li XJ (2008) N-terminal mutant huntingtin associates with mitochondria and impairs mitochondrial trafficking. J Neurosci 28: 2783-92

Panov AV, Gutekunst CA, Leavitt BR, Hayden MR, Burke JR, Strittmatter WJ, Greenamyre JT (2002) Early mitochondrial calcium defects in Huntington's disease are a direct effect of polyglutamines. Nat Neurosci 5: 731-6

Pearce I, Heathfield KW, Pearce MJ (1977) Valproate sodium in Huntington chorea. Arch Neurol 34: 308-9

Perkins MN, Stone TW (1982) An iontophoretic investigation of the actions of convulsant kynurenines and their interaction with the endogenous excitant quinolinic acid. Brain Res 247: 184-7

Qing H, He G, Ly PT, Fox CJ, Staufenbiel M, Cai F, Zhang Z, Wei S, Sun X, Chen CH, Zhou W, Wang K, Song W (2008) Valproic acid inhibits Abeta production, neuritic plaque formation, and behavioral deficits in Alzheimer's disease mouse models. J Exp Med 205: $2781-9$

Rajanikant GK, Zemke D, Senut MC, Frenkel MB, Chen AF, Gupta R, Majid A (2007) Carnosine is neuroprotective against permanent focal cerebral ischemia in mice. Stroke 38: 3023-31

Ramaswamy S, McBride JL, Kordower JH (2007) Animal models of Huntington's disease. ILAR J 48: 356-73

Reiner A, Albin RL, Anderson KD, D'Amato CJ, Penney JB, Young AB (1988) Differential loss of striatal projection neurons in Huntington disease. Proc Natl Acad Sci U S A 85: 5733-7 
Robotka H, Sas K, Agoston M, Rozsa E, Szenasi G, Gigler G, Vecsei L, Toldi J (2008) Neuroprotection achieved in the ischaemic rat cortex with L-kynurenine sulphate. Life Sci 82: 915-9

Rouaux C, Panteleeva I, Rene F, Gonzalez de Aguilar JL, Echaniz-Laguna A, Dupuis L, Menger Y, Boutillier AL, Loeffler JP (2007) Sodium valproate exerts neuroprotective effects in vivo through CREB-binding protein-dependent mechanisms but does not improve survival in an amyotrophic lateral sclerosis mouse model. J Neurosci 27: $5535-45$

Sadri-Vakili G, Cha JH (2006) Histone deacetylase inhibitors: a novel therapeutic approach to Huntington's disease (complex mechanism of neuronal death). Curr Alzheimer Res 3: 403-8

Saft C, Lauter T, Kraus PH, Przuntek H, Andrich JE (2006) Dose-dependent improvement of myoclonic hyperkinesia due to Valproic acid in eight Huntington's Disease patients: a case series. BMC Neurol 6: 11

Sapko MT, Guidetti P, Yu P, Tagle DA, Pellicciari R, Schwarcz R (2006) Endogenous kynurenate controls the vulnerability of striatal neurons to quinolinate: Implications for Huntington's disease. Exp Neurol 197: 31-40

Sattler R, Xiong Z, Lu WY, Hafner M, MacDonald JF, Tymianski M (1999) Specific coupling of NMDA receptor activation to nitric oxide neurotoxicity by PSD-95 protein. Science 284: $1845-8$

Schilling G, Becher MW, Sharp AH, Jinnah HA, Duan K, Kotzuk JA, Slunt HH, Ratovitski T, Cooper JK, Jenkins NA, Copeland NG, Price DL, Ross CA, Borchelt DR (1999) Intranuclear inclusions and neuritic aggregates in transgenic mice expressing a mutant N-terminal fragment of huntingtin. Hum Mol Genet 8: 397-407

Schmitt ML, Graeff FG, Carobrez AP (1990) Anxiolytic effect of kynurenic acid microinjected into the dorsal periaqueductal gray matter of rats placed in the elevated plus-maze test. Braz J Med Biol Res 23: 677-9

Schmitz C, Schuster D, Niessen P, Korr H (1999) No difference between estimated mean nuclear volumes of various types of neurons in the mouse brain obtained on either isotropic uniform random sections or conventional frontal or sagittal sections. J Neurosci Methods 88: 71-82 
Schwarcz R (2004) The kynurenine pathway of tryptophan degradation as a drug target. Curr Opin Pharmacol 4: 12-7

Schwarcz R, Guidetti P, Sathyasaikumar KV, Muchowski PJ (2010) Of mice, rats and men: Revisiting the quinolinic acid hypothesis of Huntington's disease. Prog Neurobiol 90: $230-45$

Schwarcz R, Hokfelt T, Fuxe K, Jonsson G, Goldstein M, Terenius L (1979) Ibotenic acidinduced neuronal degeneration: a morphological and neurochemical study. Exp Brain Res 37: 199-216

Schwarcz R, Whetsell WO, Jr., Mangano RM (1983) Quinolinic acid: an endogenous metabolite that produces axon-sparing lesions in rat brain. Science 219: 316-8

Sharma D, Shinchuk LM, Inouye H, Wetzel R, Kirschner DA (2005) Polyglutamine homopolymers having 8-45 residues form slablike beta-crystallite assemblies. Proteins 61: 398-411

Shehadeh J, Fernandes HB, Zeron Mullins MM, Graham RK, Leavitt BR, Hayden MR, Raymond LA (2006) Striatal neuronal apoptosis is preferentially enhanced by NMDA receptor activation in YAC transgenic mouse model of Huntington disease. Neurobiol Dis 21: $392-403$

Smith Y, Raju DV, Pare JF, Sidibe M (2004) The thalamostriatal system: a highly specific network of the basal ganglia circuitry. Trends Neurosci 27: 520-7

Song C, Zhang Y, Parsons CG, Liu YF (2003) Expression of polyglutamine-expanded huntingtin induces tyrosine phosphorylation of N-methyl-D-aspartate receptors. J Biol Chem 278: 33364-9

Stack C, Ho D, Wille E, Calingasan NY, Williams C, Liby K, Sporn M, Dumont M, Beal MF (2010) Triterpenoids CDDO-ethyl amide and CDDO-trifluoroethyl amide improve the behavioral phenotype and brain pathology in a transgenic mouse model of Huntington's disease. Free Radic Biol Med 49: 147-58

Stahl WL, Swanson PD (1974) Biochemical abnormalities in Huntington's chorea brains. Neurology 24: 813-9

Steffan JS, Bodai L, Pallos J, Poelman M, McCampbell A, Apostol BL, Kazantsev A, Schmidt E, Zhu YZ, Greenwald M, Kurokawa R, Housman DE, Jackson GR, Marsh 
JL, Thompson LM (2001) Histone deacetylase inhibitors arrest polyglutaminedependent neurodegeneration in Drosophila. Nature 413: 739-43

Stone TW, Perkins MN (1981) Quinolinic acid: a potent endogenous excitant at amino acid receptors in CNS. Eur J Pharmacol 72: 411-2

Sun Y, Savanenin A, Reddy PH, Liu YF (2001) Polyglutamine-expanded huntingtin promotes sensitization of N-methyl-D-aspartate receptors via post-synaptic density 95 . J Biol Chem 276: 24713-8

Symington GR, Leonard DP, Shannon PJ, Vajda FJ (1978) Sodium valproate in Huntington's disease. Am J Psychiatry 135: 352-4

Taberner PV, Charington CB, Unwin JW (1980) Effects of GAD and GABA-T inhibitors on GABA metabolism in vivo. Brain Res Bull 5(Suppl. 2): 621-5

Takahashi T, Kikuchi S, Katada S, Nagai Y, Nishizawa M, Onodera O (2008) Soluble polyglutamine oligomers formed prior to inclusion body formation are cytotoxic. Hum Mol Genet 17: 345-56

Tang TS, Tu H, Chan EY, Maximov A, Wang Z, Wellington CL, Hayden MR, Bezprozvanny I (2003) Huntingtin and huntingtin-associated protein 1 influence neuronal calcium signaling mediated by inositol-(1,4,5) triphosphate receptor type 1. Neuron 39: 227-39

Tavares RG, Tasca CI, Santos CE, Alves LB, Porciuncula LO, Emanuelli T, Souza DO (2002) Quinolinic acid stimulates synaptosomal glutamate release and inhibits glutamate uptake into astrocytes. Neurochem Int 40: 621-7

The Huntington's Disease Collaborative Research Group (1993) A novel gene containing a trinucleotide repeat that is expanded and unstable on Huntington's disease chromosomes. Cell 72: 971-83

Thomas EA, Coppola G, Desplats PA, Tang B, Soragni E, Burnett R, Gao F, Fitzgerald KM, Borok JF, Herman D, Geschwind DH, Gottesfeld JM (2008) The HDAC inhibitor 4b ameliorates the disease phenotype and transcriptional abnormalities in Huntington's disease transgenic mice. Proc Natl Acad Sci U S A 105: 15564-9

Thompson PD, Berardelli A, Rothwell JC, Day BL, Dick JP, Benecke R, Marsden CD (1988) The coexistence of bradykinesia and chorea in Huntington's disease and its implications for theories of basal ganglia control of movement. Brain 111 (Pt 2): 22344 
Truant R, Atwal RS, Desmond C, Munsie L, Tran T (2008) Huntington's disease: revisiting the aggregation hypothesis in polyglutamine neurodegenerative diseases. FEBS J 275: 4252-62

Vamos E, Fejes A, Koch J, Tajti J, Fulop F, Toldi J, Pardutz A, Vecsei L (2010) Kynurenate derivative attenuates the nitroglycerin-induced CamKIIalpha and CGRP expression changes. Headache 50: 834-43

Vamos E, Pardutz A, Varga H, Bohar Z, Tajti J, Fulop F, Toldi J, Vecsei L (2009a) 1kynurenine combined with probenecid and the novel synthetic kynurenic acid derivative attenuate nitroglycerin-induced nNOS in the rat caudal trigeminal nucleus. Neuropharmacology 57: 425-9

Vamos E, Voros K, Zadori D, Vecsei L, Klivenyi P (2009b) Neuroprotective effects of probenecid in a transgenic animal model of Huntington's disease. J Neural Transm 116: $1079-86$

van Vugt JP, van Hilten BJ, Roos RA (1996) Hypokinesia in Huntington's disease. Mov Disord 11: 384-8

Vecsei L, Beal MF (1991a) Comparative behavioral and neurochemical studies with striatal kainic acid- or quinolinic acid-lesioned rats. Pharmacol Biochem Behav 39: 473-8

Vecsei L, Beal MF (1991b) Comparative behavioral and pharmacological studies with centrally administered kynurenine and kynurenic acid in rats. Eur J Pharmacol 196: $239-46$

von Horsten S, Schmitt I, Nguyen HP, Holzmann C, Schmidt T, Walther T, Bader M, Pabst R, Kobbe P, Krotova J, Stiller D, Kask A, Vaarmann A, Rathke-Hartlieb S, Schulz JB, Grasshoff U, Bauer I, Vieira-Saecker AM, Paul M, Jones L, Lindenberg KS, Landwehrmeyer B, Bauer A, Li XJ, Riess O (2003) Transgenic rat model of Huntington's disease. Hum Mol Genet 12: 617-24

Vonsattel JP, Myers RH, Stevens TJ, Ferrante RJ, Bird ED, Richardson EP, Jr. (1985) Neuropathological classification of Huntington's disease. J Neuropathol Exp Neurol 44: $559-77$

Vriend JP, Alexiuk NA (1996) Effects of valproate on amino acid and monoamine concentrations in striatum of audiogenic seizure-prone Balb/c mice. Mol Chem Neuropathol 27: 307-24 
Walker FO (2007) Huntington's disease. Lancet 369: 218-28

Wellington CL, Ellerby LM, Hackam AS, Margolis RL, Trifiro MA, Singaraja R, McCutcheon K, Salvesen GS, Propp SS, Bromm M, Rowland KJ, Zhang T, Rasper D, Roy S, Thornberry N, Pinsky L, Kakizuka A, Ross CA, Nicholson DW, Bredesen DE, Hayden MR (1998) Caspase cleavage of gene products associated with triplet expansion disorders generates truncated fragments containing the polyglutamine tract. J Biol Chem 273: 9158-67

West MJ (2002) Design-based stereological methods for counting neurons. Prog Brain Res 135: 43-51

Wheeler VC, Auerbach W, White JK, Srinidhi J, Auerbach A, Ryan A, Duyao MP, Vrbanac V, Weaver M, Gusella JF, Joyner AL, MacDonald ME (1999) Length-dependent gametic CAG repeat instability in the Huntington's disease knock-in mouse. Hum Mol Genet 8: 115-22

Young AB, Greenamyre JT, Hollingsworth Z, Albin R, D'Amato C, Shoulson I, Penney JB (1988) NMDA receptor losses in putamen from patients with Huntington's disease. Science 241: $981-3$

Zeise ML, Kasparow S, Zieglgansberger W (1991) Valproate suppresses N-methyl-Daspartate-evoked, transient depolarizations in the rat neocortex in vitro. Brain Res 544: $345-8$

Zeron MM, Hansson O, Chen N, Wellington CL, Leavitt BR, Brundin P, Hayden MR, Raymond LA (2002) Increased sensitivity to N-methyl-D-aspartate receptor-mediated excitotoxicity in a mouse model of Huntington's disease. Neuron 33: 849-60

Zhang H, Das S, Li QZ, Dragatsis I, Repa J, Zeitlin S, Hajnoczky G, Bezprozvanny I (2008) Elucidating a normal function of huntingtin by functional and microarray analysis of huntingtin-null mouse embryonic fibroblasts. BMC Neurosci 9: 38

Zuccato C, Tartari M, Crotti A, Goffredo D, Valenza M, Conti L, Cataudella T, Leavitt BR, Hayden MR, Timmusk T, Rigamonti D, Cattaneo E (2003) Huntingtin interacts with REST/NRSF to modulate the transcription of NRSE-controlled neuronal genes. Nat Genet 35: 76-83 